\title{
Los historiadores de la generación del centenario: sus cartas juveniles
}

\section{The historians of the centennial generation: their youthful letters}

Lucila Castro de Trelles ${ }^{1}$

\section{Resumen}

El artículo presenta el contexto histórico y fragmentos, así como cartas inéditas de Jorge Guillermo Leguía, Emilia Romero, Jorge Basadre y Raúl Porras Barrenechea, que muestran en parte cómo y en qué pensaban aquellos historiadores jóvenes de la llamada generación del centenario.

Palabras clave: Generación del centenario, Centenario de la Independencia del Perú, Guillermo Leguía, Jorge; Romero, Emilia; Basadre, Jorge; Porras Barrenechea, Raúl

\section{Abstract}

The article presents the historical context and fragments, as well as unpublished letters of Jorge Guillermo Leguía, Emilia Romero, Jorge Basadre and Raúl Porras Barrenechea, which show in part how and what those young historians of the socalled centennial generation thought.

1 Historiadora, exalumna de la PUCP e investigadora. Correspondencia (Corresponding author): lucilacastromendivil@gmail.com

Código ORCID: 0000-0003-3528-0754 
Key words: Centennial generation, Centennial of the Independence of Peru, Guillermo Leguía, Jorge; Romero, Emilia; Basadre, Jorge; Porras Barrenechea, Raúl

En vísperas de celebrar el bicentenario de la República, me encontraba dando los últimos toques a un trabajo sobre la correspondencia amorosa de Jorge Guillermo Leguía con su novia, Emilia Romero, mientras estuvo preso en 1933 acusado de apoyar la rebelión del comandante Gustavo Jiménez, apodado El Zorro, contra el presidente Sánchez Cerro. En la búsqueda de información sobre ellos, encontré en el archivo de la Biblioteca Nacional de México (BNM) numerosas cartas y documentos de ambos personajes y de compañeros de Jorge Guillermo Leguía pertenecientes a la generación del centenario: Raúl Porras Barrenechea y Jorge Basadre. Igualmente, encontré valiosos documentos en el Archivo de la Casa Museo Basadre en Tacna (ACMBT). Por ello, he creído pertinente presentar en este artículo algunos fragmentos de las cartas inéditas entre ellos, así como tres cartas completas, inéditas también, que van en los anexos. En ellas muestran en parte cómo y en qué pensaban aquellos historiadores jóvenes de la llamada generación del centenario.

Para la historiografía, las cartas constituyen una fuente fundamental para conocer la personalidad de los protagonistas. Son testimonios espontáneos de lo privado que registran aspectos íntimos; son, por lo tanto, un acceso a ámbitos del mundo interior que rodean a los personajes que se desea estudiar. Al mismo tiempo, el epistolario tiene gran valor documental e histórico, porque nos permite conocer el contexto político y social que caracterizó la vida de los autores. Las cartas que presento de los tres historiadores, manifiestan algunos rasgos de su personalidad, las relaciones de amistad 
entre ellos y la forma como se dedicaron al quehacer histórico durante su época universitaria.

Luis Alberto Sánchez tiene una mención especial en este grupo y si bien es más literato que historiador, pertenece a la generación del centenario porque estudiaron juntos en San Marcos, participó con ellos en las luchas universitarias y en los trabajos de investigación en la Biblioteca Nacional $y$, sobre todo, porque a través de su gran producción literaria nos ha legado innumerables y valiosos testimonios sobre sus compañeros de la generación.

El hilo conductor para entender y describir la relación entre los tres historiadores es Jorge Guillermo Leguía. Por ello, presento algunos datos precisos de su biografía. Jorge Guillermo Leguía Iturregui nació en Lima (1898-1934) en una familia de origen lambayecano, cuyas raíces provienen del país vasco. Su padre fue Germán Leguía y Martínez, quien destacó como un hombre ilustrado, jurista, escritor y político. En 1919, asumió el premierato en el tercer gabinete del oncenio de su primo, el presidente Augusto B. Leguía. Lo apodaron El Tigre por la fiereza y dureza con que actuó contra los adversarios del régimen. La infancia de Jorge Guillermo transcurrió en diferentes provincias adonde su padre fue enviado para cumplir funciones administrativas y judiciales. En 1917, en pleno gobierno de José Pardo, Jorge Guillermo ingresó a la Universidad Nacional Mayor de San Marcos y tuvo como compańeros, entre otros, a Raúl Porras Barrenechea (1897-1960) y a Luis Alberto Sánchez (1900-1994). Jorge Basadre (1903-1980), si bien era varios años más joven que sus compañeros, en la universidad se acopló rápidamente a ellos y participó en las actividades culturales, literarias, de investigación y de reflexiones históricas que realizaban.

2 Sobre la vida y obra de Jorge Guillermo Leguía, véase la tesis de Guzmán Sánchez (1997). 


\section{La generación del centenario}

La vida estudiantil de los jóvenes de la generación del centenario fue activa, tanto académica como políticamente, durante los inicios del oncenio. Muchos de sus profesores eran miembros de la llamada generación del 900, que surgió a principios del siglo XX como una corriente cultural que absorbió el positivismo reinante en San Marcos y que luego "se adhieren al espiritualismo del Ariel de José Enrique Rodó" (Castilla 2011; 141-142). Por ello será llamada también la generación arielista o futurista porque entre sus integrantes figuraba uno de los ideólogos del partido Nacional Democrático, llamado también partido futurista (Guerra Martinière, 1984, t. XII, pp. 70-71). Entre los destacados miembros de esa generación figuran José de la Riva-Agüero y Osma (1885-1944), Víctor Andrés Belaunde (1883-1966), los hermanos Francisco (1883-1953) y Ventura (1886-1959) García Calderón, Luis Fernán Cisneros (1882-1954), Julio C. Tello (1880-1947) y Oscar Miró Quesada (1884-1981). La mayoría de ellos, de familias acomodadas, nacieron en los años de la guerra del Pacífico, vivieron la tragedia de la postguerra y de la guerra civil y luego el proceso de la reconstrucción nacional. Estos jóvenes pensaban que esa reconstrucción nacional no solo debía tener como meta el aspecto económico, sino que debía ahondarse y profundizar la conciencia de una identidad nacional (Denegri Luna, 1994, p. 220). Se proyectaron hacia el estudio del presente, de la realidad nacional en diferentes aspectos y tuvieron influencia en la formación de los miembros de la siguiente generación, sobre todo, en los historiadores de la generación del centenario.

Influyeron en ellos personajes notables, como Víctor Andrés Belaúnde, quien con su charla La vida universitaria en el local de la Federación marcó el preámbulo de la reforma universitaria. Igualmente, impactaron las clases de sus maestros Carlos Wiesse en historia del Perú, Felipe Barreda y Laos en 
historia de América y las clases magistrales de José de la Riva Agüero, que siempre causaban gran admiración (Guzmán Sánchez, 1997, pp. 25, 32). En sus primeros años universitarios se produjeron una serie de acontecimientos políticos que marcaron el oncenio de Leguía y la vida de estos estudiantes.

El expresidente Leguía se hallaba en el exilio en Londres desde 1913 y preparaba su retorno al Perú como candidato. En 1918, a través de la correspondencia con Melitón Porras y partidarios suyos, Leguía organizó comités que apoyasen su candidatura para las elecciones de 1919 (Capuñay 1951: 140-144; no cita el origen de esta correspondencia). Los universitarios de San Marcos tuvieron un papel protagónico en este renacimiento de Leguía; apoyaron con entusiasmo su nuevo proyecto y lo eligieron Maestro de la Juventud en octubre de 1918 con 314 votos de un total de 467. Es cierto que posteriormente la vorágine política los distanció y los mismos estudiantes le quitaron el título. Para esa nueva etapa, Leguía enarboló una bandera: la Patria Nueva como un ideal frente al envejecido civilismo. Para Ombeline Dagicour (2010), que analiza el mito Leguía y sus símbolos, la Patria Nueva representa el proyecto político que busca la modernización económica y la construcción de un nuevo Estado peruano. Simboliza la idea de la regeneración y refundación de una realidad política, económica y social. Leguía prometió una era de prosperidad, una nueva edad de oro, un porvenir glorioso con el régimen de la Patria Nueva y elaboró para ello un discurso nacionalista y patriótico que buscaba crear una conciencia y movilizar a las clases medias y populares.

Leguía llegó al Perú en febrero de 1919 y el recibimiento por parte de los universitarios fue triunfal. La Federación de Estudiantes envió a Panamá al alumno de medicina Felipe Chueca como delegado para recibirlo. Se organizó una gran movilización a través de avisos en las páginas de El Comercio y de los comités para su recibimiento en el Callao. El ingreso 
a Lima por la avenida La Colmena fue apoteósico. Avanzó en coche descubierto hasta su residencia en la calle Pando mientras saludaba y ondeaba su sombrero agradeciendo las flores y aplausos. Sánchez, como testigo presencial, afirma que los manifestantes vitoreaban: «iLa Patria Nueva!», «iA la redención de Tacna, Arica y Tarapacá!» y protestaban contra la carestía de las subsistencias (1969, t. I, p. 278). Probablemente, Jorge Guillermo y sus amigos también estuvieron aclamando a Leguía en esos momentos.

Como estudiante, Jorge Guillermo se involucró en las luchas universitarias secundado por sus compañeros, entre los que se encontraban Raúl Porras y Luis Alberto Sánchez. Ellos, además, estuvieron motivados por la presencia de Haya de la Torre, en ese entonces joven alumno de 22 ańos, que acababa de regresar de Argentina decidido a organizar la federación de estudiantes y preparar la reforma universitaria siguiendo los patrones de la denominada reforma de Córdoba. Jorge Guillermo fue elegido presidente del Comité de Huelga de la Facultad de Letras de San Marcos por su ponderación y buen ánimo y porque representaba la rebeldía de aquella época junto con Haya de la Torre, José Manuel Calle, Manuel Bastos, José León y Bueno, Luna Cartland, Luis Alberto Sánchez y Raúl Porras. Los lunes en la noche se reunían en casa de Raúl Porras “(...) para conversar, leer, y discutir los temas políticos, y preparar la reforma universitaria" (Sánchez, 1982, t. I, p. 9). La casa de Raúl Porras quedaba en esa época en la calle Mariquitas, en la tercera cuadra del jirón Moquegua, y fue durante muchos ańos el centro de reunión y tertulia de los jóvenes universitarios. Posteriormente, Porras consciente de su importancia y con gran capacidad de convocatoria y espíritu organizador, retomó las reuniones en su casa de Miraflores (actual sede del Instituto Raúl Porras Barrenechea). Ahí reunía a colegas, investigadores y discípulos para las grandes tertulias con la ventaja de que se podía consultar su valiosa biblioteca. Todos ellos ayudaron a fijar las orientaciones de la reforma universitaria que cambia- 
rían las estructuras de la Universidad de San Marcos. Según el historiador Cueto Caballero, la universidad sobrevivió al civilismo, pero se rompió la idea tradicional de ella y se buscó una «universidad libre» con renovación de cátedras para echar a los malos profesores, difundir la cultura mediante seminarios y conversatorios y proveer una serie de beneficios a los estudiantes (1982, pp. 143-144).

Posteriormente, Jorge Guillermo junto con sus compañeros organizaron el Conversatorio Universitario, donde buscaban investigar y rehacer la historia de la Independencia del Perú, de manera que esta no fuera solo una narración erudita de nombres, fechas, batallas, carentes del espíritu y alma de su época. A ese grupo de jóvenes reformistas que replantearon el tema de la independencia y ofrecieron conferencias públicas se les llamó a partir de ese evento la generación del centenario. Los jóvenes disertantes del Conversatorio fueron Raúl Porras Barrenechea sobre José Joaquín Larriva; Jorge Guillermo Leguía sobre Lima en el siglo XVIII; Luis Alberto Sánchez sobre Los poetas de la revolución, y Manuel G. Abastos sobre los aspectos ideológicos de ese período (Basadre 1968, t. XV, pp. 335-336).

Si bien el interés por la investigación histórica predominó en esos estudiantes, también había otros, unos años mayores, que vivían «apasionadamente el tema social y la realidad presente». Ellos tuvieron una clara vocación política con un nuevo radicalismo social fruto del impacto de la revolución rusa y la aparición del movimiento indigenista. Los más representativos fueron Antenor Orrego, José Carlos Mariátegui, Víctor Raúl Haya de la Torre e Hildebrando Pozo, entre otros (Guerra Martinière 1984, t. XII, pp. 70-71).

Al mismo tiempo, Raúl Porras organizó un grupo para catalogar la colección Papeles Varios de la Biblioteca Nacional que ocupaba numerosos estantes de la sección Perú en la sala Amé- 
rica. Cuenta Basadre, quien acababa de ingresar a la universidad y unirse al grupo, que el trabajo de fichaje era gratuito y voluntario, pero se dedicaron a él con gran empeńo y lograron terminar uno de los estantes de Papeles Varios (Basadre, 1975, p. 347). La tarea era catalogar la colección, que tenía encuadernados sin orden más de 15,000 folletos impresos desde la época colonial hasta la republicana y eran fuentes documentales valiosas para la investigación de nuestra historia.

Basadre afirma que el viaje de Raúl Porras a México paralizó la obra, pero que él siguió en el trabajo acompañado siempre de Jorge Guillermo Leguía y Manuel Abastos. En ese momento, tenía dieciséis años y abandonó definitivamente la perspectiva de entrar en uno de los grandes estudios de Lima para ser abogado (p. 5). Posteriormente, Jorge Basadre entró como auxiliar y luego como "conservador» a trabajar en la Biblioteca Nacional, donde pasó toda su etapa estudiantil. Alternó su trabajo en la biblioteca con la docencia universitaria y luego se especializó en bibliotecas en los Estados Unidos mediante una beca de la Dotación Carnegie.

Desde esta época empezó la profunda y fraterna amistad entre Jorge Guillermo Leguía y Jorge Basadre. Forjaron una relación tan sólida que, según testimonio del mismo Basadre «duraría intacta y sin sombra a lo largo de dieciséis años». Lo llamaba su hermano del alma o hermano mayor y fue su confidente a lo largo de los ańos (1975, pp. 239-240; 1989, p. 17). A su vez, Jorge Guillermo lo llamaba su Colombroño.

Los jóvenes historiadores colaboraron con diversos trabajos periodísticos en la revista Germinal, que era el órgano de la liga universitaria. También publicaron en el diario La Prensa y en revistas, como Variedades y Mundial. ${ }^{3}$ Jorge Guiller-

3 Hay colaboraciones de Jorge Basadre en la revista Amauta en los números 4 y 7. Igualmente, de Luis Alberto Sánchez en los números 4, 21,25 y 29. 
mo publicaba sistemáticamente sus estudios y documentos en la sección Domingos Históricos, que creó desde mayo de 1921 hasta octubre de 1922. En ella, aparecieron artículos con pequeñas biografías de Castilla, Manuel González Prada, Pizarro, Vigil y Salaverry, entre otros, con los que buscaban difundir entre la gran masa popular, carente de medios económicos, el conocimiento histórico y despertarle el sentido de conciencia y de identidad nacional, más aún cuando se vivía el año del centenario de la independencia del Perú. Ese afán divulgador del quehacer intelectual fue un tema permanente en la vida de los tres jóvenes historiadores.

La enseñanza en los colegios particulares fue un recurso que caracterizó a las grandes figuras de la generación del centenario para poder financiar sus estudios y gastos personales. Se ayudaban económicamente con la enseñanza en colegios como el Anglo Americano o el colegio alemán Deutsche Schule. Por sus aulas pasaron maestros como Jorge Guillermo Leguía, Raúl Porras, Luis Alberto Sánchez y Jorge Basadre. Según este último, los animaba un sincero amor a la enseñanza, pues deseaban dar «una visión viva y directa de lo que aparentemente era árido y monótono» (Foto 1 y 2 de la generación del centenario).

También es importante señalar la participación activa de los tres historiadores en la revista Mercurio Peruano, creada por Víctor Andrés Belaúnde para difundir temas sobre el Perú. Jorge Guillermo fue el secretario de 1920 a 1922 y luego Raúl Porras tomó la posta. La revista publicaba mensualmente artículos, poemas, conferencias y traducciones de ellos mismos y de otros intelectuales de la época, y representaba la esencia cultural de esos tiempos.

Cuando llegaron las celebraciones por el centenario de la independencia en julio de 1921, tanto Jorge Guillermo Leguía como Raúl Porras debieron tener un arduo trabajo. El 


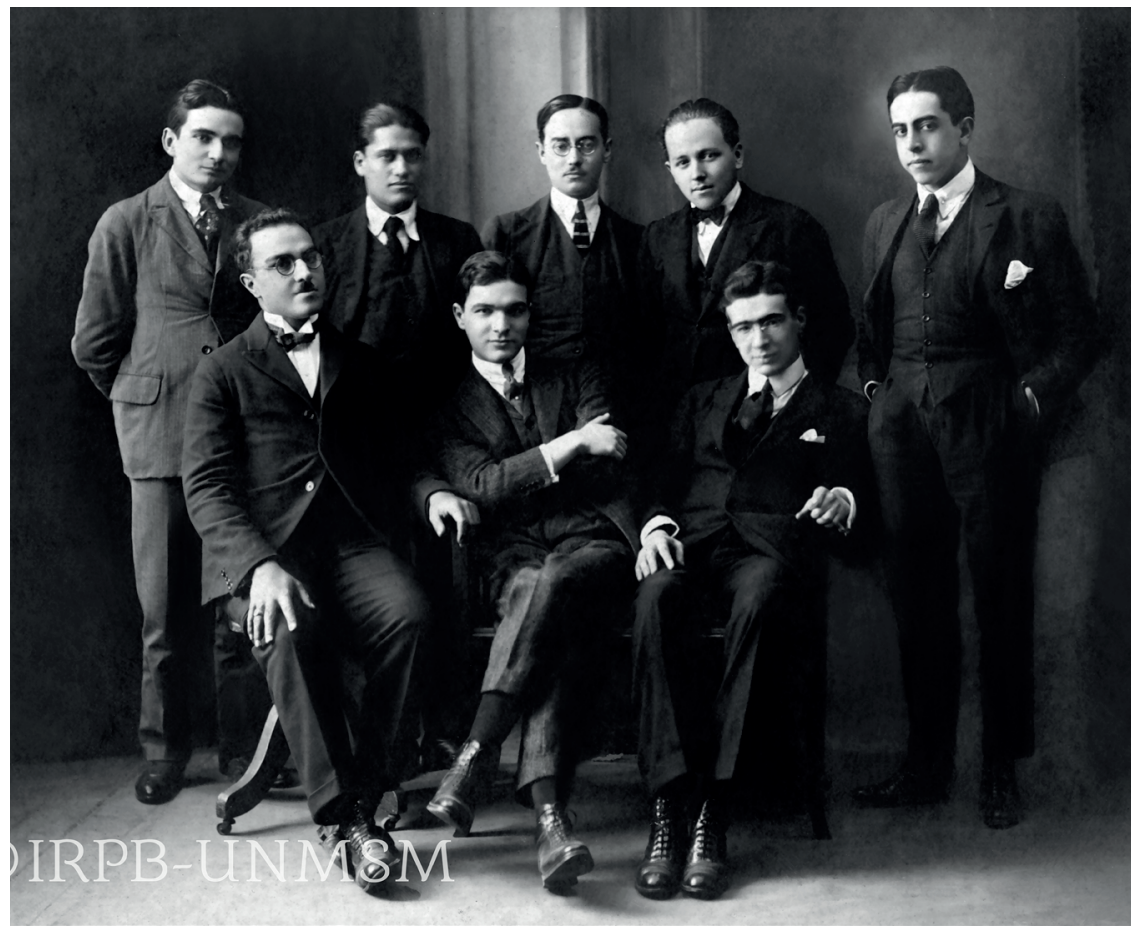

Conversatorio Universitario, 1919. De pie: Jorge Basadre, Manuel G. Abastos, Ricardo Vegas García, Raúl Porras Barrenechea y Luis Alberto Sánchez. Sentados: Guillermo Luna Cartland, Carlos Moreyra Paz

272 Soldán y Jorge Guillermo Leguía. (cortesía IRPB). 


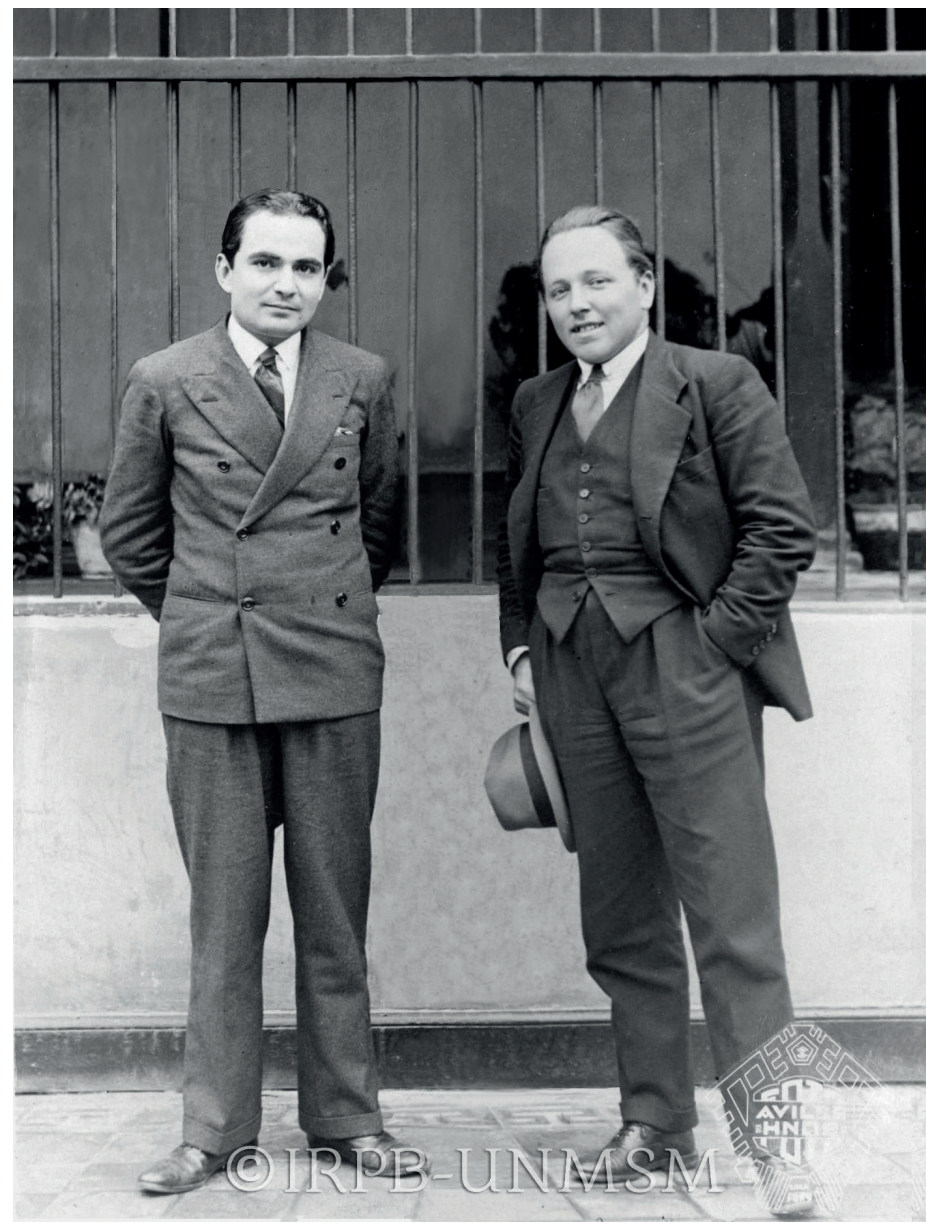

Jorge Basadre y Raul Porras Barrenchea en el Museo Nacional de Historia. (Cortesía IRPB). 
primero, como subsecretario del presidente, función que desempeñaba desde julio de 1919. Entre sus múltiples obligaciones tenía a su cargo redactar los discursos de este para las inauguraciones y ceremonias conmemorativas, y el segundo, como ayudante en el servicio diplomático asistiendo a todas las delegaciones invitadas. Las celebraciones fueron fastuosas, las colonias extranjeras ofrecieron múltiples regalos que se fueron entregando a lo largo de los años. Se celebraron banquetes, bailes, corridas de toros, proyecciones cinematográficas, galas hípicas y fiestas populares. Lima estaba engalanada, se construían avenidas, parques y malecones, y la ceremonia central fue la inauguración de la plaza San Martín. ${ }^{4}$

\section{Cartas de Raúl Porras desde México, 1921}

En setiembre de 1921, Raúl Porras fue enviado con una delegación de estudiantes para participar en el Congreso Panamericano en México con motivo de su centenario. Con su característico humor sarcástico, el 15 de setiembre Raúl Porras le escribió a Jorge Guillermo una carta en la que le comenta los detalles del inicio de la celebración del centenario de México.

Hoy es el grito de Hidalgo y a las diez de la noche el Presidente de la República tocará en el Palacio de Gobierno, en el balcón que cae sobre la plaza principal, la misma histórica campana con que convocara a la libertad el glorioso cura de Dolores. Será una ceremonia histórica en la que revivirá la ciudad dieciochesca, cuyo recuerdo se evoca aquí a cada instante por obra de los grandes y numerosos monumentos que aquí, con más generosidad que en Lima, dejaron los españoles.

Durante ese viaje oficial a México, Raúl Porras pudo comprobar el grato recuerdo que tenían los invitados del centena-

4 Sobre las celebraciones del centenario, véase Casalino (2017). 
rio de Lima. En esa misma carta, se queja de la mala atención y organización del gobierno mexicano, de los estudiantes del congreso y de la falta de protocolo para las delegaciones invitadas. Afirma que el descuido oficial tiene un notable contraste con el entusiasmo y el orden de nuestro centenario. «El embajador y el secretario colombianos, decían al desembarcar en Veracruz, de pie en un remolcador sucio y estrecho, que iban a extrañar en todo la cortesía limeña». Luego, que: «(...) en las fiestas oficiales no se hacen las atenciones debidas ni se tienen las condecoraciones al rango distintivo de las personas. Reina todavía un desorden revolucionario y predominan los improvisados».

La carta manuscrita que se presenta en el Anexo 1 es la segunda que envía Raúl Porras a Jorge Guillermo desde México el 23 de setiembre de 1921 y tiene siete páginas pequeñas. En ella, vuelve a insistir en lo disgustada que se encuentra la delegación peruana por la desorganización reinante del gobierno, de los estudiantes y del protocolo. Le informa que Roca, jefe de la delegación peruana, tuvo que improvisar un discurso porque no le habían avisado de ese formalismo. Luego se jacta con orgullo, que después de varios debates sobre esos problemas de desorganización, terminó siendo elegido por aclamación vicepresidente del congreso con la ayuda de Antonio Reyes, delegado de la Liga Panamericana y de la delegada neoyorquina. En la misiva, Raúl se muestra feliz y orgulloso con ese nombramiento y se da tiempo para recordar con fina ironía cómo los alemanes al votar pronunciaban su nombre estirando las letras erres: "Porrrrras".

En esa carta hace referencia a José Vasconcelos, figura prominente como escritor y símbolo de la cultura mexicana, y lo critica porque con el gran presupuesto que manejaba, mantenía con puestos y prebendas a los centroamericanos expulsados de sus países que asisten al congreso representándolos y se atribuían todas las iniciativas e intervenciones en los debates. 
Luego, describe jocosamente la presencia inesperada en México del maestro Víctor Andrés Belaúnde, que se hallaba en el extranjero por haber sido exilado por el gobierno de Leguía. Porras en la carta hace una comparación entre Belaúnde y Vasconcelos en el sentido de que ambos tienen la misma chifladura, «la democracia». Dice que Vasconcelos, por su parte, quiere derrocar la dictadura de Gómez en Venezuela y lo ataca en todos sus discursos para que se unan contra él todos los pueblos de América. Por su parte, Porras afirma que Belaúnde pretende hacer lo mismo y que de manera soterrada critica al gobierno de Leguía, predicando que los pueblos «oprimidos por tiranos no podrían estrechar sus relaciones con los pueblos libres». Escribe casi con burla que Belaúnde se muestra como el representante del espíritu democrático y popular, mientras que Leguía representa al capitalismo, que Víctor Andrés llegó hasta inventarse un supuesto episodio de fusilamiento del gobierno para intimidarlos. Porras, otra vez con sorna, dice que disiparon el autoincienso de las palabras de Belaúnde «haciéndole comprender al periodista que era un obsesionado». Estos comentarios del exilado ponían en una situación incómoda a la delegación peruana enviada oficialmente por el gobierno de Leguía. Porras finaliza la carta alabando la conducta ética de Belaúnde, que retractándose ante el periodista, borró del reportaje las frases duras referidas al gobierno de Leguía. Siempre elegante, Porras termina la carta con la frase: «a tout seigneur tout honneur».

Aparte del interés de los hechos que narra, la carta del anexo 1 muestra la pluma magistral, la prosa irónica pero certera y la capacidad de análisis psicológico y del alma que tenía el maestro Porras.

\section{Cartas de Jorge Guillermo en el destierro}

En 1922 se produjo una ruptura política entre don Germán Leguía y Martínez y el presidente Augusto B. Leguía por no estar de acuerdo con la reelección presidencial y el Tra- 
tado Salomón-Lozano. Eso llevó a que tan pronto como el Congreso aprobó la reelección presidencial, ese mismo día renunció Germán Leguía y Martínez a su cargo de premier y ministro de Gobierno, y Jorge Guillermo, su hijo, al cargo de subsecretario de la presidencia de la República. El ambiente político de esa época se fue caldeando con la corriente del germancismo, que proponía a don Germán como candidato presidencial, pero dicha candidatura no prosperó. Posteriormente, hubo una conjura en varios medios periodísticos que lo acusaron falsamente de intentar derrocar al gobierno de Leguía promoviendo una insurrección militar con documentos fraguados por los civilistas. Como consecuencia de ello, en la madrugada del 15 de noviembre de 1923 Germán Leguía y Martínez fue apresado en su domicilio junto con sus hijos Jorge Guillermo y Óscar. Aquella noche será llamada por Jorge Guillermo «la noche de San Barthelemy», asemejándola quizás por su intensidad con la masacre a los protestantes en el siglo XVI. Ambos fueron detenidos en la Prefectura y luego trasladados a la isla San Lorenzo, a la misma prisión que había habilitado su padre para los conspiradores y rebeldes contra el gobierno del presidente Leguía. Luego de catorce días fueron embarcados hacia Panamá, ciudad donde eran exilados los personajes incómodos para el régimen. Así empezó el destierro de cuatro años de nuestro joven historiador, que lo alejó de su familia, de su carrera universitaria y de sus compañeros y amigos. Las cartas fueron en ese largo lapso el medio fundamental de comunicación con ellos.

Sobre el destierro de Jorge Guillermo se tenían datos sueltos, había muy poca información por la falta de fuentes históricas, pero ahora con las cartas que se han encontrado en los archivos ya mencionados, se pueden reconstruir momentos de su vida durante su estancia en Panamá y en Costa Rica. ${ }^{5}$

5 En el Fondo Valle de la Biblioteca Nacional de México se encuentra una nutrida y extensa correspondencia inédita que Jorge Guillermo mantuvo 
La primera carta que Jorge Guillermo le escribió a Jorge Basadre, su querido tocayo y amigo del alma, del 16 de diciembre de 1923, fue a los diez días de haber llegado a Panamá. En ella, le describe minuciosamente cual cronista colonial cada paso que sufrió desde que irrumpieron violentamente, en la madrugada, las fuerzas del orden en su casa hasta la llegada a Panamá. Es una narración vibrante y dolorosa por las incomodidades y aislamiento que vivieron en la isla San Lorenzo durante catorce días. Le cuenta que una de las pocas cosas que llegaron de su familia a la isla fueron cuatro tomos de Plutarco, de Tucídides y Jenofonte que le alegraron el espíritu. Le dice: «No hay duda, Colombroño: ¡los clásicos son el cimiento!». Luego le describe el gran comportamiento que tuvo hacia ellos la oficialidad alemana a bordo del Radamés: «El buque y sus tripulantes nos parecían la gloria. [...] Buenas horas me pasaba en la torre del capitán, hojeando los derroteros y reviviendo en las memorias mis predilectos estudios de geografía». Posteriormente, le narra el arribo a $\mathrm{Pa}$ namá, cómo se instalaron en el hotel Corcó frecuentado por muchos exilados, como Castro Pozo, Luján, Encinas y Roca que habían tenido que partir hacia San José de Costa Rica porque el costo de vida resultaba más barato. El desarraigo y la falta de medios económicos fueron un martirio adicional para los exilados.

La siguiente carta que se presenta en el Anexo 2 está escrita por Jorge Guillermo el 27 de enero de 1924, dirigida nuevamente a Basadre. Es una carta manuscrita, inédita,

desde el destierro con varias personalidades e intelectuales del Perú, como Víctor Andrés Belaúnde, Víctor Raúl Haya de la Torre (diez cartas), Raúl Porras Barrenechea (catorce cartas) y Jorge Basadre (dos cartas). Igualmente, la correspondencia familiar de Jorge Guillermo con su padre mientras estuvo en Costa Rica (quince cartas); las cartas de Jorge Guillermo a su madre mientras estuvo en Panamá (once cartas) y las cartas desde Panamá de su padre, Germán Leguía a su esposa en Lima (quince cartas). 
bastante extensa, de once páginas. En ella, Jorge Guillermo muestra un entusiasmo desbordante por haber recibido por fin una carta de su amigo Jorge Basadre. Desde el inicio se percibe la inmensa alegría que sintió cuando su padre le entregó la misiva, después de setenta días sin recibir ninguna carta de sus compañeros, donde la emoción era tan fuerte que no le permitía comprender el contenido, pues devoraba los párrafos escritos. Es una misiva llena de informaciones en la que supone que su tocayo ya habrá recibido los folletos escritos por su padre como vocal de la Corte Suprema, con respecto a la elección del nuevo presidente de la Corte en el Perú. También le informa que le ha enviado una carta al presidente Leguía, en la que niega tajantemente las acusaciones que le imputaba de haber falsificado documentos con papeles membretados de la Presidencia de la República. ${ }^{6}$

En esta etapa inicial del destierro, Jorge Guillermo y su padre tenían un ánimo de venganza, de castigo y de lucha contra el presidente Leguía y afirmaron que no defraudarán «las esperanzas cifradas en nosotros». Tomó conciencia de que cualquier reacción contra el régimen «(...) ha de partir de las provincias, y nosotros haremos cuanto esté de nuestra parte para que así sea». Pensaban que no estarían mucho tiempo en Panamá por el excesivo calor, por la distancia con el Perú, y porque creían que Leguía podía caer en cualquier momento. Pero a medida que pasaba el tiempo fueron tomando conciencia de las circunstancias reales, de la estabilidad del régimen y, por lo tanto, de la necesidad de reunir a la familia que se había quedado en Lima: la madre, dos hijas y dos hijos. En

6 Jorge Guillermo le escribe al presidente Leguía una carta titulada: Un estudiante peruano en el destierro se dirige al Presidente Leguía, el 10 de diciembre de 1923 (BNM, Fondo Valle). Fue publicada en Panamá y también en el Repertorio Americano como Carta al Presidente Leguía. San José de Costa Rica, 3 agosto de 1925, t. X, No. 21. 
un principio, don Germán pensó en mudarse a Costa Rica, pero no lo hicieron a pesar de que Jorge Guillermo estuvo durante varios meses en San José buscando la casa ideal capaz de albergar a toda la familia.

En la carta aparecen variadas noticias y comentarios precisos sobre las actividades conspirativas de los civilistas Héctor Escardó y Alaiza Roel y del general La Fuente. Los comentarios sobre el coronel Óscar R. Benavides, de acuerdo con la información que le brindó Roca, son negativos y resaltan el apoyo que los civilistas le brindaban para un posible levantamiento. Como nada ocurría, estaban cansados de mantenerlo económicamente. Es interesante señalar cómo desde esa época los civilistas veían a Benavides como una alternativa para derrocar a Leguía. Las noticias que escribe Jorge Guillermo sobre Balta acerca de su soborno mientras fue director del Ramo de Petróleo y del romance con una tonadillera fueron la comidilla de los exilados. Eran verosímiles y muy comprometedoras para su reputación. Entre los exilados había una avidez y necesidad urgente por todo tipo de noticias relacionadas con gente del Perú.

Jorge Guillermo le comenta en esa carta sobre el artículo que ha escrito Raúl Porras como una «maravilla de delicadeza literaria». Se siente feliz por su amigo, porque lo ve «cuajado». Y piensa que puede ser el mejor prólogo para la colección de poesías que publicará Rafael Heliodoro Valle. Le menciona sobre otras cartas recibidas y las respuestas. Se muestra muy agradecido por haber ayudado a su familia en el traslado de sus cosas personales, libros y objetos de minería de su casa a la casa de sus tías Rosas, pues aparentemente su madre y hermanos habrían tenido que abandonar la casa alquilada donde vivían. La situación económica de los Leguía Martínez en el destierro era precaria y dura. No hay certeza de cuándo le enviaron a su padre el sueldo o la pensión que le correspondía como vocal supremo, ni siquiera si lo hicieron. Lo cierto es 
que el resto de la familia que quedó en Lima se manejaba con un presupuesto mínimo y para ahorrar el alquiler tuvieron que refugiarse donde los Rosas hasta que lograron, después de varios meses, darles el encuentro en Panamá, como se ha mencionado. Jorge Guillermo le agradece emocionado a su amigo Basadre por la generosidad de su espíritu al ayudar a su familia en esos momentos tan críticos para él. Y le abre su alma, le cuenta sus intimidades, sus sinsabores, la monotonía de su vida, el calor enervante que lo agobia. Está en un momento de amargura, de pesimismo total, de lo que él llama «sus estallidos de afecto». Le expresa «(...) ¡en este infierno uno se siente un animal!». Hace reflexiones sobre el valor de su amistad cuando todos lo han abandonado, negado y probablemente vituperado, inclusive muchos de su misma sangre. Sin embargo él, su tocayo, nunca dudó de su correcto comportamiento y por ello se siente gratificado por su amistad. La descripción del comienzo de su viaje y forzoso exilio hacia la prisión de la isla San Lorenzo, viendo cómo la costa se alejaba con el parpadeo de las luces de Lima y un futuro incierto sobre el retorno refleja su profunda desolación y la tristeza de partir hacia el exilio.

Jorge Guillermo comparte con él cada momento de la vida en Panamá, con sus alegrías, angustias y malestares. Por momentos es una carta íntima, personal, con diferentes estados de ánimo. Se nota que Jorge Guillermo todavía no ha asumido que el destierro durará un buen tiempo y, por tanto, no ha organizado su vida y sus investigaciones históricas de largo plazo. Con el pasar de los meses, Jorge Guillermo se matriculó en el Panama College para estudiar inglés y empezó a colaborar activamente con diversos artículos en la revista $E$ studios y en la Ley de Panamá con el seudónimo de Mercátor, que había utilizado desde sus épocas escolares. Raúl Porras desde Lima lo anima a escribir sobre la Historia de América, proyecto que culminó en el extranjero. Dicho trabajo tuvo repercusiones internacionales, pues al redactarse el programa 
de Historia de México para las escuelas secundarias, el Colegio de Profesores de esa disciplina «tuvo muy en cuenta el manual de Leguía para su elaboración» (Valle, 1934). También se abocó a terminar su estudio sobre Gálvez y Cáceres, entre otros trabajos.

\section{Carta de Raúl Porras a Jorge Guillermo sobre el Centena- rio de Ayacucho 1924}

Mientras tanto, en el Perú Leguía había sido reelegido como presidente en 1924 y a pesar de las protestas de algunos grupos opositores se preparaban nuevas celebraciones por el centenario de Ayacucho, que pretendían ser mejores y más fastuosas que las de 1921. El alejamiento forzado del Perú le impidió a nuestro joven historiador estar presente en Lima para dichas celebraciones y gozó de ellas a través de las cartas de sus amigos que redactaban afanosamente trabajos históricos para ser publicados en diarios y revistas.

Raúl Porras le informó lo recargada que estaba su vida en esos momentos previos al centenario. Le escribió que entre sus tareas en el Colegio Anglo Americano, el trabajo en el ministerio y la labor de bibliotecario, casi no tenía tiempo para las investigaciones históricas que tanto le seducían. Le cuenta que «(...) los periódicos anuncian vastas ediciones conmemorativas para un inusitado despliegue histórico» (Cartas de Raúl Porras a Jorge Guillermo Leguía. 12 octubre de 1924. BMN, Fondo Valle). Tanto la revista Mundial como La Crónica le solicitaron cola-

282 boraciones. A la primera, entregó una monografía sobre Lima, y a la segunda, sobre Ayacucho. También ofreció a Variedades un escrito sobre las tentativas peruanas de la Independencia. Y a Mackay, director del Colegio Anglo Americano, «(...) le he prometido dar una conferencia en el Colegio sobre la contribución inglesa a la Independencia del Perú: audacia de Cochrane, intrepidez de Miller y las libras esterlinas del empréstito...». 
En la misma carta, Porras, ufanándose de su autoría, le transcribe la lista detallada de los intelectuales invitados al centenario de Ayacucho, que representan lo más selecto de la cultura hispanoamericana.

Sabrá Ud. ya que habrá gran concurrencia intelectual para el Centenario. En Panamá presenciará Ud. el conspicuo desfile. Vendrá Rabindranath Tagore que ya aceptó la invitación. De la Argentina, probablemente Lugones, Rojas, Capdevilla. De México Antonio Caso y Núnez y Domínguez, pues Díaz Mirón se ha excusado en sus achaques e indigencia. De Cuba Márquez Sterling y Fernández Ross. El viejo Varena no puede venir. Centro América estará representada por Santiago Argüello, Fernández Guardia, Heliodoro Valle, Cardona, Rodríguez Cerna y Gavidia. De Panamá en vez de invitarse a Méndez Pereira se ha invitado a Obarrio. De Colombia a Marco Fidel Suárez, monseñor Carrasquilla y Sanin Cano. De Venezuela Tito Salas, Vallenilla Lanz y Vicente Lecuna. Del Brasil a don Joaquín da Costa da Campos de Alburquerque, Rodrigo Octavio y Alfonso Celso. Del Uruguay a Zorrilla de San Martín. Del Paraguay a Juan Stefanich. De Bolivia a Jaymes Freyre y Franz Tamayo. De Santo Domingo a Tulio Cestero. Del Ecuador a Honorato Vásquez y Crespo Toral. No faltarán por supuesto los consuetudinarios don J. León Suárez, Tassi, Santa Cruz y el nieto de un reciente héroe uruguayo Garzón. De España se ha invitado a Ortega y Gasset, D’Ors y Valle Inclán. Por la lista comprenderá Ud. a quién se deben determinadas invitaciones y el buen gusto literario que ha presidido a éstas.

Sobre los destacados invitados que llegaron a Lima por el centenario de Ayacucho, menciono un nombre importante: la presencia del poeta, historiador y periodista Rafael Heliodoro Valle por la estrecha vinculación que tendrá con los tres historiadores que se analizan. ${ }^{7}$ Valle era hondureño de nacimiento y radicaba en México, donde gozaba de gran

7 Sobre la figura e importancia de Rafael Heliodoro Valle como humanista de América, véase Chapas Bezanilla (2004). 
prestigio como profesor universitario y periodista por sus numerosas publicaciones. Había conocido a Raúl Porras en el Congreso en México de 1921 y desde ese momento comenzó la relación de amistad que se extendió a los demás amigos historiadores, incluido Luis Alberto Sánchez, con una profusa correspondencia e intercambio de datos, informaciones, libros y publicaciones durante años. La venida a Lima como invitado del centenario de Ayacucho convirtió a Valle en un amigo y profundo admirador del Perú, cuyos lazos lo unieron para siempre con nuestra patria. Pasadas las celebraciones, le escribió a Raúl Porras lo siguiente:

En vano cierro los ojos para ver en la bruma del recuerdo la ciudad maravillosa. Eso ya solo es una visión que pasó, efímera pero inolvidable. Lima tiene su veneno y habrá que volver ¿Cuándo? No lo sé, pero volveré. Ustedes fueron tan buenos, tan cordiales, especialmente usted, a pesar de sus travesuras cotidianas, que son ya permanentes en la memoria, y cada vez que haya que pensar en algo grato, tenemos que recordarlos. (Carta de Rafael Heliodoro Valle a Raúl Porras, 29 de abril de 1925. BNM, Fondo Valle, ERHC EXP 195, 1921-1953.)

\section{Retorno a Lima de Jorge Guillermo Leguia}

El destierro llegó a su fin para la familia Leguía y Martínez después de cuatro largos años. El padre de Jorge Guillermo se encontraba muy delicado de salud y, ante ello, el presidente Leguía les autorizó el regreso al Perú y llegaron a Lima el 9 de marzo de 1927. Jorge Guillermo le cuenta en una carta a Víctor Andrés Belaúnde que el cáncer maligno de su padre le ha quitado el tiempo y el ánimo para proseguir con sus investigaciones históricas. Le informa apenado que quizás solo podrá concluir la biografía de José Gálvez el próximo año, luego se ocupará de escribir las vidas de Luna Pizarro, Mariátegui, Benito Laso, etc. para completar su galería de liberales (Carta de Jorge Guillermo Leguía a Víctor Andrés Belaúnde. 23 de octubre de 1927. AHIRA). 
$\mathrm{Al}$ año siguiente de su llegada al Perú, se produjo la pérdida de dos de sus seres queridos que afectó doblemente a la familia Leguía y Martínez. Primero falleció el seis de agosto su hermano Julio, de veintiseis años, con quien había compartido el destierro en Panamá y a quien llamaba Nato. ${ }^{8} Y$ tres meses después murió su padre don Germán Leguía y Martínez el 21 de noviembre de 1928.

La enfermedad terminal de su padre propició el acercamiento a su tío, el presidente Augusto B. Leguía, y en 1928 Jorge Guillermo fue incorporado como catedrático de historia del Perú y de historia de América en la Universidad de San Marcos, y ocupó dichos cargos hasta 1934. Lo más importante de esa reconciliación fue su nombramiento como director del Museo Bolivariano, cargo que desempeñó con gran dedicación desde el 8 de setiembre 1928 al 28 de agosto de 1930, en que renunció apenas se produjo la caída de Augusto B. Leguía. Jorge Guillermo afirmaba que el Museo Bolivariano debía ser no solo el relicario del Libertador y sus hechos, sino un «nexo más estrecho con los pueblos que recogieron su trascendental influencia».?

Lo más resaltante durante su período como director del museo fue la creación y edición del valioso Boletín Bolivariano destinado a difundir los temas de la emancipación. En él se publicaron documentos inéditos, que constituyen un gran

8 Relación de los hijos del matrimonio Germán Leguía y Martínez. BNM, Fondo Valle.

9 Palabras que mencionó Jorge Guillermo Leguía en el discurso que dio en el Museo Bolivariano el 24 de julio de 1929, con la presencia del presidente Augusto B. Leguía a raíz de la entrega al museo del facsímil del testamento del libertador Simón Bolívar por el embajador de Venezuela. Fue publicado en el Boletín del Museo Bolivariano, número 2, pp. 41b-415 en agosto de 1929. Ver el N. ${ }^{\circ} 173$ y Romero (1940), p. 47. 
aporte documental y bibliográfico para el estudio de la Independencia. Según el doctor José Agustín de la Puente, Jorge Guillermo Leguía fue el historiador de los grandes liberales peruanos; su gran aporte dio mayor fuerza al tiempo precursor y publicó textos que no estaban difundidos. Margarita Guerra Martinièri (1984) señala que es casi el único repertorio para documentos como El elogio al Virrey de Jáuregui, Las 28 causas de Riva Agüero y también dio a conocer personajes casi olvidados de nuestra historia, como Mariano José de Arce, Manuel Pérez de Tudela y José Baquíjano y Carrillo, entre otros (t. VIII, pp. 486-487). Los números del Boletín Bolivariano eran esperados con mucho interés y reclamados por los intelectuales de los países americanos. El Museo Bolivariano se convirtió en un centro de reunión de muchos intelectuales y amigos que lo visitaban, entre ellos Raúl Porras y Jorge Basadre, que aparecen en la foto junto con Jorge Gibson y otros como Adolfo Westphalen, Carlos Fernández Stoll, Estuardo Núñez, etc. (Foto 3 y 4 en el Museo Bolivariano).

Abundan anécdotas sobre la amistad que tenían los jóvenes de la generación del centenario con Jorge Guillermo. Por ejemplo, la narrada tanto por Basadre como por Luis Alberto Sánchez. Cuentan que un día que agasajaron a Jorge Guillermo con un almuerzo por su cumpleaños, pusieron en la mesa a su derecha un asiento vacío y, junto al cubierto huérfano, la tarjeta de don Manuel Lorenzo Vidaurre y Encalada de quien estaba escribiendo una biografía y vivía obsesionado recogiendo sus datos (Sánchez, 1989, p. 17). La investigación sobre Vidaurre que estaba trabajando desde varios años era muy importante para Leguía, pues era el tema central para su tesis de doctorado que lamentablemente no pudo finalizar.

Después de la caída de Leguía, Jorge Guillermo asumió cargos administrativos y académicos en la Universidad de San Marcos. Cuando el 23 de marzo 1931 se graduó de bachiller en letras, al día siguiente lo nombraron por unanimidad 


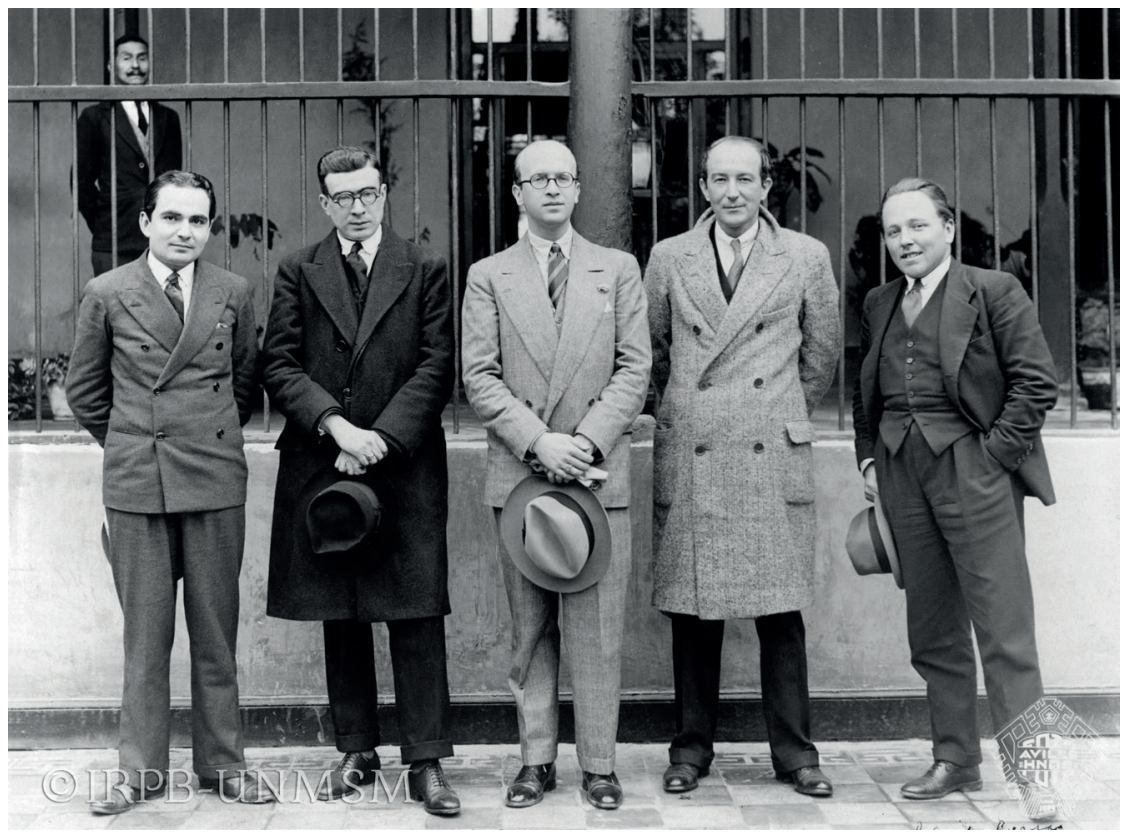

Museo Bolivariano de Magdalena. Jorge Basadre, Jorge Guillermo Leguía, H. Ruiz Diaz Percy Gibson y Raúl Porras Barrenechea. (1928). Cortesía del IRPB. 
Secretario General de la Universidad siendo rector el doctor Encinas. Mantuvo ese cargo hasta su muerte.

\section{La generación desventurada}

La caída de Leguía y la persecución a los leguiistas, el golpe de Sánchez Cerro y su nuevo gobierno, el levantamiento aprista y su represión sanguinaria, así como las demandas populares agudizaron los reclamos políticos universitarios que llevaron a la clausura de la Universidad de San Marcos en reiteradas ocasiones. Esto perjudicó enormemente el desenvolvimiento de la universidad pues, suprimidas las clases, muchos estudiantes terminaron por emigrar al extranjero para proseguir sus estudios y graduarse. Otros vieron retrasada su formación y los profesores y funcionarios se quedaron sin sueldo. Dramática era la situación para los miembros de la generación del centenario. Porras la llama "generación desventurada». Para Guerra Martinièri, el nombre de generación del centenario o "generación vetada» se debe a que empezó a actuar durante el oncenio amordazada y proscrita salvo para aquellos que ingresaban al servicio oficial (1984, t. XII, pp. 70-71). Víctor Raúl Haya de la Torre se refiere a ellos como: «(...) la generación de historiadores 19-20, Porras-Basadre-Leguía. Lo importante de esa generación es que inició el movimiento de la emancipación mental indoamericana, punto de partida de lo que Laín Entralgo llama vagido de una nueva cultura...» (Sánchez, 1982, t. II, p. 94).

288 Jorge Guillermo Leguía durante el periodo de 1930 al 1933 sufrió dos prisiones acusado de conspiración, por llevar el apellido Leguía según Luis Alberto Sánchez; una, a raíz del levantamiento de los marineros apristas en 1932 y otra, como ya he señalado, en marzo de 1933 con el levantamiento del Zorro Jiménez en Cajamarca.

En medio de esa situación tan inestable, Jorge Guillermo se 
enamoró apasionadamente de Emilia Romero, joven limeña con grandes inquietudes intelectuales. ${ }^{10}$ Era hija de Eulogio Romero Salcedo, primo hermano del expresidente Leguía, que ocupó el cargo de presidente del Banco Central durante todo el oncenio. Para sus compañeros de letras fue una verdadera sorpresa el romance tan apasionado de Jorge Guillermo, que ofrecía una imagen seria y más bien formal propia de un intelectual dedicado íntegramente a la enseñanza y a la investigación. Cuando Luis Alberto Sánchez regresó al Perú después del destierro, encontró a este: «[...] como antes, más sobrio sí, pero igualmente sonriente y generoso, y ahora, ahora enamorado... Nuestro Topsius... había hallado el camino del amor» (Sánchez, 1989, p. 18). Y el amor se encendió todavía más a raíz de los dos meses que estuvo en prisión. Durante ese período se escribieron las cartas más tiernas, románticas y apasionadas. Los amantes se juraron amor eterno y decidieron casarse. Sin embargo, dichos sueńos fueron truncados violentamente, porque la muerte cegó tempranamente la vida de nuestro joven historiador. Jorge Guillermo murió en enero de 1934, a los 35 años de edad, siete meses después de haber salido de la prisión. Al parecer, su deceso fue producto de una tuberculosis que debió gestarse desde aquellos días en prisión que desgastaron su frágil salud.

Sus grandes amigos de la generación del centenario no pudieron acompañarlo en sus últimos días ni el día de su entierro. Raúl Porras, ya dedicado al servicio diplomático, se encontraba en la Delegación Peruana en Río de Janeiro con la jefatura de Víctor Andrés Belaúnde. Su tocayo, Jorge Basadre, estaba radicado en Madrid, después de haber pasado un buen tiempo en Sevilla entre investigaciones y clases.

10 Emilia Romero hizo la primera traducción del francés de Peregrinaciones de una paria de Flora Tristán (1947) y Dos viajeros franceses en el Perú republicano de E. de Sartiges (1947). Véanse todas sus publicaciones en Romero (1966), 278-279. 
Luis Alberto Sánchez se hallaba escondido, perseguido por su filiación aprista. Sin embargo, al sepelio acudieron otros amigos y profesores y un buen número de estudiantes que querían y estimaban muchísimo al "maestro» y secretario de San Marcos.

Con la prematura muerte de Jorge Guillermo Leguía, los otros dos historiadores tomaron distintos derroteros, pero comprometidos siempre con la investigación histórica. Raúl Porras siguió ligado al servicio diplomático, a la cátedra universitaria y a la producción historiográfica de temas coloniales. Jorge Basadre dirigió un tiempo la Biblioteca Nacional del Perú, siguió también con sus clases en la Universidad de San Marcos y se convirtió en el gran historiador de la República.

Después de esa tragedia personal tan dolorosa y traumática para Emilia Romero en vísperas de casarse, quedó postrada en un profundo desconsuelo y solo después de varios meses pudo dedicarse fervorosamente a la publicación y reedición póstuma de las obras finales e inconclusas de su adorado Jorge Guillermo. Para ello, tomó contacto con los amigos de su «novio» e inició una fluida correspondencia con ellos, sobre todo con Jorge Basadre y Raúl Porras.

\section{Carta de Jorge Basadre a Emilia Romero}

El contexto de esta tercera carta de Jorge Basadre a Emilia

290 Romero es el siguiente. Previamente a ella, Emilia le escribió una carta a Jorge Basadre, a quien no conocía personalmente porque estaba radicado en España, pero de quien había escuchado hablar sobre su calidad personal y amistad íntima con Jorge Guillermo. En ella, le cuenta los últimos acontecimientos ocurridos con la publicación de las conferencias sobre Ricardo Palma. En febrero de 1933, para celebrar el centenario de Palma, Raúl Porras había organizado la Sema- 
na de Palma con una serie de conferencias, charlas radiales y veladas musicales. Las conferencias centrales estuvieron a cargo de Raúl Porras Palma romántico, de Víctor Andrés Belaúnde Palma politico, y de Jorge Guillermo Leguía Don Ricardo Palma. En la conferencia que dio Jorge Guillermo en el local de la Sociedad Geográfica se produjo una polémica con José de la Riva Agüero (maestro y amigo suyo) por la afirmación que hizo Jorge Guillermo de que don Ricardo Palma no habría estudiado en el Colegio de San Carlos (Riva Agüero, 1962). Había llegado a esa conclusión porque al revisar los archivos del Convictorio de San Carlos no había encontrado ninguna matrícula, ni notas, ni documento alguno que revelaran la huella del paso de Ricardo Palma por sus aulas. Pero Riva Agüero demostró que había sido alumno libre. Un año más tarde, ya fallecido Jorge Guillermo, se publicaron las conferencias de la Semana de Palma, pero extrañamente no incluyeron la suya. Emilia pensó que se había cometido una injusticia porque consideraba que era una pieza literaria e histórica importante y decidió publicarla. Y se la envió a Jorge Basadre comentándole los sucesos ocurridos en una carta.

El documento que se presenta en el Anexo 3 es la respuesta de Jorge Basadre a la misiva de Emilia Romero. Es una carta manuscrita, inédita, escrita en trece páginas de hojas pequeñas desde Barcelona el 24 de julio de 1934. En sus párrafos iniciales muestra extrañeza y asombro por la decisión tomada con respecto a la no inclusión de la conferencia de Jorge Guillermo, pues le parece una bella y sólida contribución, cuyos puntos de vista y conceptos lo han sorprendido gratamente. Basadre no entiende la conducta de Riva Agüero contra Jorge Guillermo cuando lo acusa de jacobino, a raíz de un discurso suyo en la inauguración de la Biblioteca de la Universidad Católica. Afirma con toda la admiración que siente por Riva Aguero que dicha conducta lo ha asombrado y pasmado por incomprensiva e injusta. 
La carta es un verdadero y sentido homenaje a la figura de Jorge Guillermo y resalta sus cualidades personales, su generosidad, rectitud y su permanente apoyo. Es un elogio a su persona y a su vocación histórica. Era el «amigo que sabía apoyar y acompañar». Con una profunda tristeza dice que cuando retorne al Perú ya no estará él y se sentirá «inmensamente más solo». Sobre los aportes de Jorge Guillermo, menciona una auténtica e irrevocable vocación por la cultura, la que puso al servicio del Perú y de América. «Le entusiasmaban las figuras ejemplares, los aristócratas de la inteligencia y de la cultura». Alaba su obra tardía e incompleta. En Vidaurre dice que se encuentra un Jorge Guillermo más maduro, malicioso y socarrón que penetra en todos los rincones de su personaje. Destaca su afán de ir construyendo la historia civil del Perú.

Por último, reflexiona sobre su muerte temprana, que explica por qué publica poquísimo frente a lo mucho que dejó inédito; por lo tanto, será una labor incompleta. "Con la muerte de los jóvenes se trunca lo más inmenso que hay: las posibilidades». Concluye la carta con el consuelo de que en los últimos tiempos halló la felicidad al lado de Emilia. La carta de Basadre es un bello testimonio de amistad; sorprende por la franqueza y emotividad de sus palabras, sin que por ello deje de trasmitir con precisión y objetividad sus opiniones sobre la personalidad y obra de su compañero y amigo Jorge Guillermo Leguía.

Para cerrar el tema de Jorge Guillermo y Emilia, es importante conocer el papel que ella cumplió al dar a conocer y publicar su obra póstuma. Además de escribirles a sus amigos peruanos, Emilia se comunicó también con los intelectuales amigos de Jorge Guillermo que vivían en el extranjero, entre ellos, el poeta Rafael Heliodoro Valle, que tuvo un papel relevante junto a Emilia Romero. La correspondencia entre ellos se inició al principio como un intercambio meramente intelectual, de condolencias por la muerte de Jorge Guiller- 
mo, de envíos de las obras que ella le publicaba, de intercambio de revistas, de artículos, etc. Con los años el epistolario fue adquiriendo nuevos matices, tornándose personal e íntimo. Emilia Romero se había convertido en el vínculo de Valle con el Perú. Después de seis años de correspondencia epistolar con el poeta, Rafael Heliodoro Valle tomó la decisión de venir al Perú para conocerla y casarse con ella. El matrimonio tuvo lugar en Lima en 1941 y los testigos matrimoniales fueron los dos grandes amigos y compañeros de Jorge Guillermo: Raúl Porras y Jorge Basadre. El destino llevó a Emilia Romero a compartir su vida con dos grandes intelectuales: primero como novia de Jorge Guillermo Leguía y luego como esposa del poeta Valle.

Después de la boda y de un viaje por las serranías peruanas, partieron a México donde Rafael radicaba hacía muchos años. Tuvieron una agitada y productiva vida intelectual, ${ }^{11}$ en los que sobresalen los cuatro años y medio que fueron embajadores de Honduras en Washington, donde Rafael Heliodoro Valle creó el Ateneo Hispanoamericano y lo convirtió en el centro cultural americano más importante de aquella época. Valle representó una de las grandes vocaciones intelectuales donde alternó: «(...) el arte de la frase bella con la ciencia de la investigación minuciosa, la rapidez de la crónica periodística con la grave autoridad de la cátedra...» (Chapas Bezanilla, 2004, p. 289-290). Por ello y por mucho más esta autora considera a Rafael Heliodoro Valle como el "gran humanista de América». ${ }^{12}$

En 1968, ya fallecido su marido, Emilia Romero de Valle, donó a la Universidad Nacional de México toda la biblioteca

11 Las publicaciones de Emilia Romero están listadas en Romero (1966), pp. 278-279.

12 Sobre la vida y obra de Rafael Helidoro Valle, véase Chapas Bezanilla, 2004. 
que ambos habían reunido y que contenía más de 20,000 volúmenes, incluidos diversos incunables, entre ellos el manuscrito original de la independencia de Trujillo y Lambayeque. Además, para rendir un homenaje a la memoria de su esposo, creó un patronato que entrega el Premio Rafael Heliodoro Valle para destacar a los mejores historiadores y literatos de Latinoamérica. Los peruanos que obtuvieron dicho premio fueron Jorge Basadre en 1977, Luis E. Valcárcel en 1981, Javier Sologuren en 1983 y Franklin Pease en 1989.

Algunas de las cartas que se han mencionado en el presente artículo y en los anexos pertenecen al archivo denominado Fondo Valle, que guardaron celosamente Rafael Heliodoro Valle y Emilia Romero. Ese archivo, con las cartas de sus queridos y estimados colegas peruanos, nos ha permitido conocer algunas facetas y pinceladas de los historiadores de la generación del centenario.

Deseo concluir con dos citas que reflejan el estilo y personalidad de ambos historiadores: la primera, está en una carta de Jorge Basadre a Valle y muestra su constante preocupación por las bibliotecas y la segunda cita, escrita por Washington Delgado, es una magnífica descripción sobre la prosa y el estilo de Raúl Porras.

"A la bibliotecaria mexicana, seńorita Manrique de Lara me permití escribirle sobre la posibilidad de formar una asociación bibliográfica indoamericana, cuyas funciones serían análogas a las que tan admirablemente realiza aquí la American Library Association. Podría esta Asociación realizar la lista bibliográfica de las publicaciones de cada país, servir de órgano de propaganda y de consulta para todos los países atrasados en ese campo, para los estudiosos en general, cooperar al intercambio de libros entre los diversos países de nuestro continente, seleccionar listas de libros recomendables para bibliotecas hispanoamericanas y libros hispanoamericanos recomendables para bibliotecas extranjeras, editar obras interesantes bibliográficas y propiciar la regularización de 
un código bibliográfico hispanoamericano, etc. (Carta de Jorge Basadre a Raúl Porras. Nueva York, 18 de octubre de 1931. BNM, Fondo Valle ERHC EXP. 223, 1931-1949, 24 doc.)

Porras es incomparable en el manejo de las fuentes, en el hallazgo de documentos ignorados, en la lectura novedosa y sagaz de textos conocidos, en la iluminación precisa del dato revelador. Pero, además, era un artista. Psicólogo sutil, estilista refinado, poseía el don poético de la evocación que nos permite a sus lectores revivir una época, contemplar un ambiente, comprender a un personaje histórico. Su prosa cálida, sensual, graciosa destaca no solamente en el ámbito de la historia, sino también en el de la literatura peruana. (Delgado, 2008)". 
Los historiadores de la generación del centenario: sus cartas juveniles

Primera y última hoja de la carta de Raúl Porras a Jorge Guillermo Leguía

Mifues $\$ .7,25$ - teter -1921

Sx. D. Yonge gue Kegué

Liara.

cener rigeo $x X$ )

FONDO

EAFAE: : :ALLE

2 verido yonge yuilerus: Pe eduto $y$ la de Vencore

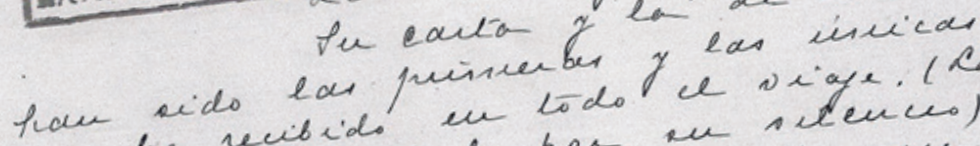
que the recibide un todo el viage. ( Ca

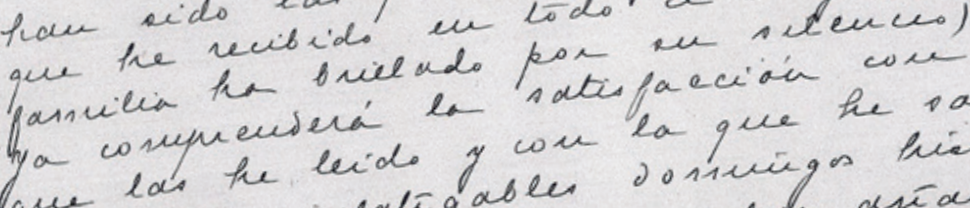
que las the leide $y$ wer la que the oa-

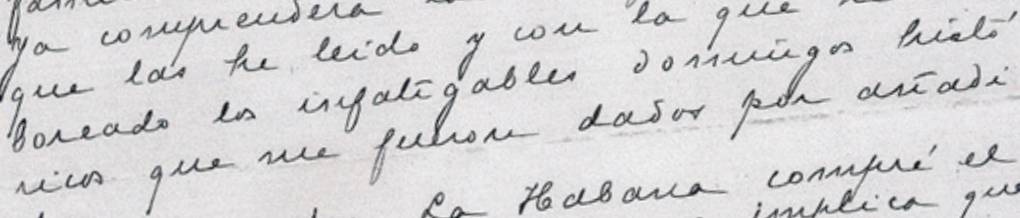

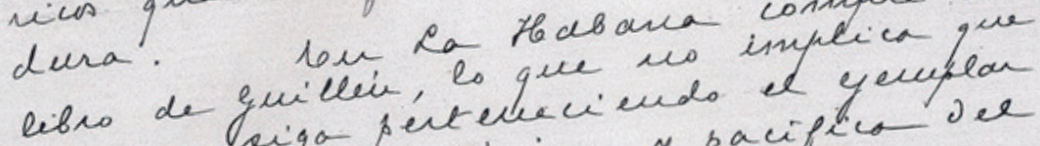

lou Ra thabana conafué el xo nue Rigo pertedeciendo el yeuplan cou dedicderia dioina y pacifico de

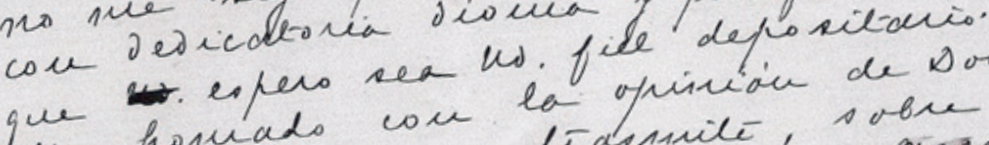

296 geviaí que W. nue teassité, sobe

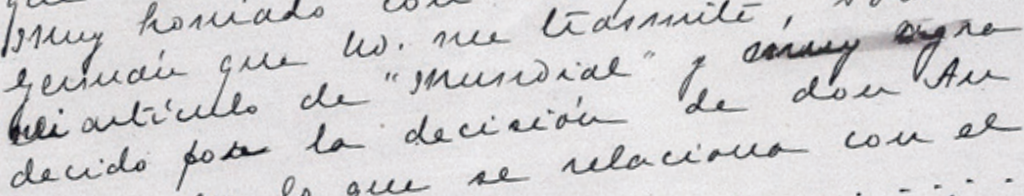
gresto, en lo que se velaciana con el

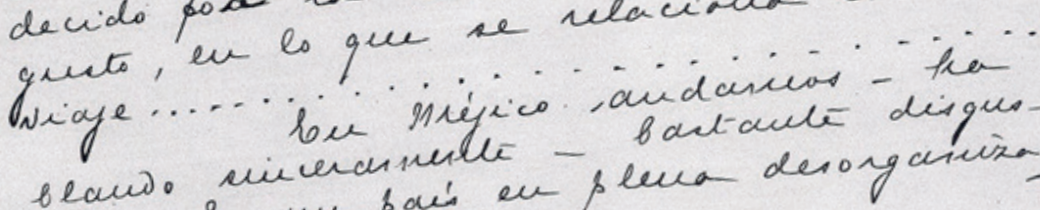

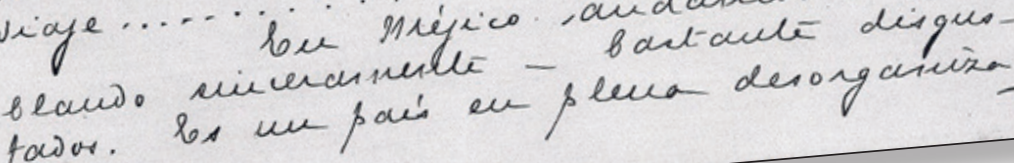

Revista del Instituto Riva-Agüero 
H Itar esta vita aporto'lica y Uerea del seute do herovico de la vidar" según él, se

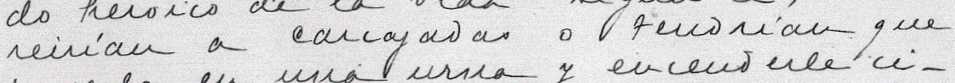
rior. Fijnenente, reosblis, disipareor algo del culo-incieuro, reud-ocero a edoa rato y haciéndale compuender al beuovistá que era un obresimado. Has ha whora ipor feliciad wo ba apare cilo neada. Pelo ya se desatará cuaudo re vaya la treubajad a porque fia

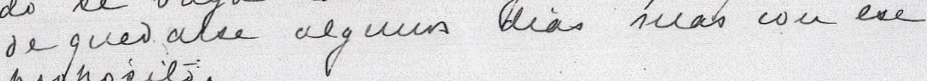
putpoidis.

por nostios osta carta de rurreude finouto Dacie Porear

P. \&. - Felinuerte Aelaunde ke tha portado comertarubite. Sus dectaraciones ai periodista funon un desahogo personal. Delaute de noovtes ha bourado del reporta je que le tiajeron esvito para que lo rebiernodee perw. Retwo peer suis prabe anteriones. It tout reiguen tout hosnem.

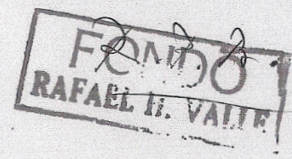




\section{Anexo 1 \\ Carta de Raúl Porras Barrenechea a Jorge Guillermo Leguía}

México DF. 23 setiembre 1921

Sr. D. Jorge Gmo. Leguía

Lima

(en el siglo XX)

\section{Querido Jorge Guillermo:}

Su carta y la de Elmore han sido las primeras y las únicas que he recibido en todo el viaje. (La familia ha brillado por su silencio). Ya comprenderá la satisfacción con que las he leído y con la que he saboreado los infatigables domingos históricos que me fueron dados por ańadidura.

En La Habana compré el libro de Guillén, lo que no implica no me siga perteneciendo el ejemplar con dedicatoria divina y pacífica del que espero sea Ud. fiel depositario. Muy honrado con la opinión de Don Germán que Ud. me trasmite, sobre mi artículo de Mundial y muy agradecido por la decisión de don Augusto, en lo que se relaciona con el viaje...

En México andamos -hablando sinceramente- bastante disgustados. Es un país en plena desorganización. Gobierno, pueblo, estudiantes y protocolo -que son los que tienen que entenderse con nosotros- sufren unas desorientaciones y unas torpezas increíbles. El protocolo tiene a cada rato disgustos con los Embajadores. El Embajador del Perú ha tenido que protestar varias veces de la falta de atención o de las molestias que le ocasionaban ayudantes petimetres del servicio protocolar. Los estudiantes por su parte no han aportado por nuestro hotel, ni a hacernos una visita de cortesía. Igual cosa nos cuentan les ha sucedido a los delegados argentinos, guatemaltecos y de la Liga Panamericana. Nosotros, siendo huéspedes, hemos tenido que apersonarnos 
en la federación. Ahí no hay con quién tratar. A la primera sesión del Congreso se olvidaron de citarnos. En la sesión inaugural, Roca tuvo que improvisar un saludo de la delegación peruana, pues todos o casi todos llevaron un discurso hecho, y probablemente solicitado por la Federación, sin que a nosotros se nos hubiera hecho ninguna advertencia. En la sesión de ayer, hice constar esos hechos y después de tomar alguna parte con Roca en los debates, conseguimos para la delegación peruana el triunfo de que se nos eligiera Vice-Presidente. La elección fue por aclamación y tuvo el mérito de producirse en favor nuestro, siendo desconocidos de casi todos los miembros, antes de la sesión, por no haber asistido a la primera reunión. Una de mis mejores ayudas para la elección fue el joven peruano I. Antonio Reyes, delegado de la Liga Pan-Americana al Congreso (enviado por el gobierno del Perú a estudiar la organización de los correos en EE.UU.), quien me declaró que aunque miembro y presidente de una delegación yanqui se ponía a mis órdenes para todo lo que fuera servir la causa del Perú. Otro entusiasta propagandista para mi elección fue la delegada new-yorkina, quien declara que el Perú es el único país de Sud-América verdaderamente amigo de los EE.UU. A esta señorita debí la agradable sorpresa de que al producirse la votación, se fueran levantando uno por uno los delegados alemanes, los bárbaros, cara Lutecia, -jlos bárbaros, cara Lutecia, los bárbaros!- y votaban con un rechinar de erres fantástico, por el señor Porrrrrras. Tuve que agradecerles en el lenguaje universal porque no entienden jota de castellano.

Toda actividad intelectual es aquí inútil. La intelectualidad que predomina en los periódicos y en la universidad es fatua y petulante. Dominan los centro-americanos expulsados por las revoluciones de sus países. Un grupo de esos adula y agasaja a Vasconcelos, rector de la universidad, que aquí tiene funciones de Ministerio de Instrucción y maneja un presupuesto de 24 millones, y éste los mantiene con puestos y prebendas. Este grupo, a pesar de no ser de estudiantes, ha logrado ingresar al Congreso, representando a sus países 
y forman una especie de mazorca autobombística, que se atribuye en los periódicos todas las iniciativas y las intervenciones en los debates. A pesar de que tengo todo dispuesto para dar mis conferencias, no sé si las abandone, en vista de esta mezquindad espiritual. Hay además un sin número de conferencias anunciadas y de conferencistas deseosos de dejarse oír. Entre ellos, nuestro Belaúnde que ha llegado aquí no sé si por desgracia. (Le dedicaré capítulo aparte). Ya han fracasado varios conferencistas por falta de público. El delegado uruguayo tuvo que suspender la suya. Pedro Henríquez Ureña se quedó sin dar una que tenía anunciada, por ese motivo.

He tenido el inmenso honor de conocer y estrechar la mano impar de don Ramón de Valle-Inclán.

Belaúnde llegó aquí el 16. Apareció de pronto en una ceremonia en la catedral con gran sorpresa nuestra. El Embajador, con mucho tino y generosidad, lo invitó a comer varias veces y le ofreció muchas de las comodidades inherentes a los diplomáticos, (automóvil, teatro, etc.). Nuestro querido Belaúnde no ha sabido corresponder a estas deferencias e hidalguías. En la Embajada tuvimos una discusión política -todos contra él- en que le probamos sus errores y apasionamientos, o sus locuras según la señora Mercedes, quien le dijo que él era el maniquí de Cisneros. Tuvo que inclinar la cabeza y hasta aceptó haberse equivocado en lo del receso universitario. Pero, fuera de la Embajada, hace una campaña subterránea y fea. Precisa darle a conocer algunos antecedentes.

Vasconcelos que es medio chiflado y con la misma chifladura de Belaúnde -jla democracia!- ha proclamado aquí la idea de que los pueblos de América deben unirse para derrocar a los tiranos. " $\mathrm{L}$ La solidaridad en la democracia, dice Belaunde, que debe suceder a la solidaridad en la independencia!" De conformidad con esta teoría, Vasconcelos predica una expedición para derrocar a Gómez, el presidente de Venezuela y el peor tirano de América. No hay 
discurso de Vasconcelos que no ataque la dictadura venezolana. Es ya una manía. Belaúnde parece que se propone incorporar a nuestro gobierno en esa lista, haciendo creer que en Lima vivimos en una época de terror, que solo él ha sentido probablemente. Así, al hablar Vasconcelos, en un banquete al que asistíamos nosotros y Belaúnde, se refirió a que el acercamiento entre los pueblos hispano-americanos dependía de su libertad. Los pueblos oprimidos por tiranos no podrían estrechar sus relaciones con los pueblos libres. Entre los pueblos libres de América que mantienen relación con México, que también es libre según él, no nombró al Perú. Era la obra subterránea de Belaúnde. Posteriormente, delante de nosotros que le rectificamos duramente -Roca y yo- se hizo una autobiografía suya a un periodista, declarándose mártir y apóstol de la libertad y usando los calificativos más canallescos contra Leguía y sus colaboradores. Quiere hacer creer que él representa el espíritu democrático y popular, y Leguía al capitalismo y (lo que es más vergonzoso, dice, al capitalismo extranjero). Llegó al cinismo después de habernos contado el día anterior toda la historia de su prisión, de querer inventar un episodio de supuesto fusilamiento para intimidarlos, episodio que según él mismo lo había relatado solo existió en su imaginación asustadiza. Si en el Perú lo oyeran contar esta vida apostólica y llena de "sentido heroico de la vida" según él, se reirían a carcajadas o tendrían que ponerlo en una urna y encenderle cirios. Felizmente, nosotros disipamos algo del auto-incienso, riéndonos a cada rato y haciéndole comprender al periodista que era un obsesionado. Hasta ahora por felicidad no ha aparecido nada. Pero ya se desatará cuando se vaya a la Embajada porque ha de quedarse algunos días más con ese propósito.

Esta carta se suspende por motivos imprevistos. Hasta muy pronto.

Raúl Porras B.

P.D. Felizmente Belaúnde se ha portado correctamente. Sus 
declaraciones al periodista fueron un desahogo personal. Delante de nosotros ha borrado del reportaje que le trajeron escrito para que lo revisara, las frases depresivas para el gobierno del Perú. Retiro pues mis frases anteriores. A tout seigneur tout honneur.

R.P.B.

En: BNM, Fondo Valle. 


\section{Anexo 2 \\ Carta de Jorge Guillermo Leguía a Jorge Basadre 1924 (ACMBT)}

Panamá, 27 de enero de 1924

Señor: Jorge Basadre Grohmann,

Lima - Colmena, No 235

Muy querido "Colobroño":

¡Qué gran sorpresa la que, con tu carta del 5 me has proporcionado esta mańana! Volvía triste del correo a las 9, cuando al entrar en mi cuarto, el Viejo, como quien hace flamear gloriosamente al viento una querida y victoriosa bandera, me enseñó las hojas temblorosas en alto, las cartas tuya, de Gustavo y de León.

Te declaro con absoluta sinceridad: en la primera lectura no entendí tu carta sino a medias: no leía, devoraba los renglones nutridos de afecto y de noticias.

- Anteayer hicieron setenta días de que solo veía una que otra carta de mi familia; y aunque siempre he alentado en mí la más ardiente fe en tu amistad, un hondo resentimiento comenzaba ya a surcar sus torturas a las infinitas que tanto me tienen amargado. Tus letras han venido a fortalecer mi convicción y a llenarme de gozo. Una vez más, querido "Colombroño": mi más íntimo agradecimiento. Entre las pocas cosas que hacen querer la vida, están las nobles y regeneradoras efusiones de la camaradería. ¡Chócala!

Nada me dices de la carta que te mandé de Paita, ni sobre mis postales.

Por el conducto "meridional" -que supongo no te traiga los novelescos sobresaltos de mi carta del 16 de diciembre- te he enviado otra carta, cuya fecha, si no recuerdo mal, es del 1 de enero, y la cual es probable acaba de llegar a tus manos. 
Presumo que de mi casa te hayan llevado algunos ejemplares de la nota del Viejo a la Suprema, y de mi carta al carajo del Leguía. En breve te irá el Manifiesto. Hace días que está terminado, pero aún no ha sido impreso.

$\mathrm{Da}$ asco lo que me refieres acerca del aplanamiento que se ha apoderado de Lima. Hay que convencerse de una verdad: la reacción ha de partir de las provincias, y nosotros haremos cuanto esté de nuestra parte para que así sea. Si la república no da señales de virilidad, eso es ya otra cosa. En tal caso, todos los peruanos están en la obligación de hacerse capar, y no tienen el derecho de quejarse de su suerte. De todos modos no defraudaremos las esperanzas que se han cifrado en nosotros.

Actualmente no perdemos el tiempo. Tratamos de restablecer nuestra red de comunicaciones. En cuanto a nuestra decisión, además de incitarnos la venganza, nos impele el ansia vehemente de castigo y de reforma.

Mil obstáculos se oponen a nuestros propósitos. El espionaje no terminó el 28 de noviembre, día que nos embarcamos en el "Radamés". En el Hotel Corcó (cuarto No 19) vive un soplón Néstor García, nombrado especialmente a raíz de nuestra deportación, para tener a Leguía al tanto de nuestras actividades. Desde antes de que García viniera a Panamá (12 de diciembre), desempeñaban la misma misión dos italianos, que se entienden directamente con el Zambo Salomón: un Maturo y un Montanari. Por más que nos fiscalicen, comerán crudo. En sus barbas los cojudeamos a cada instante y de un momento a otro les echaremos una 304 triple yuca de alta mar.

Digo esto, porque estamos resueltos a abandonar el Istmo, el cual a más de calurosísimo, está demasiado lejos del Perú. Empero, no tenemos aún seguridad de si nuestro viaje está cercano o tardará algo. Depende de las respuestas que recibamos, respuestas que no se harán esperar mucho a causa de que hemos descubierto "sendas" que ofrecen la mayor garantía. Yo te informaré de nuestros pasos. 
Hemos sabido que los civilistas se agitan febrilmente. En el "Hotel Tivoli" de Ancón -sitio adyacente a Panamá- hace un mes que trazan planes revolucionarios los ingenieros Héctor Escardó y Alaiza Roel. Aquel ha venido como plenipotenciario de los deportados de Europa y New York. Este, como enviado extraordinario de los de Lima. Afirman que cuentan en nuestra capital con el coronel La Fuente y hasta con bombas; ¡Ah cojudos! Qué risa me produce imaginar de los [ilegible] ... estarán haciendo los bribones que componen nuestro ejército.

El Benavides se halla en el desprestigio más completo. Procedente de Costa Rica llegó ayer Erasmo Roca, y nos relata que el Coronel César Enrique Pardo, pinta a aquel ladrón galoneado con los más cómicos tintes. Al llegar a Punta Arenas después de la aventura del "Paita", constituyó casa militar y Estado Mayor. Designó edecanes (sic) al sinvergüenza del Diez Canseco (que no me lea Gastón...) que se acaba de entender con Leguía, y a un Vidal. Cuando alguno de los deportados le preguntaba cuáles eran sus miras revolucionarias, le respondía que con eso corría el alto mando y le agregaba que de cuándo acá los subalternos debían estar enterados de la Campaña.

Estando en Guayaquil, y contando con una región sublevada, como la de Loreto -base importantísima de que ya hubiera querido disponer un verdadero caudillo-, se redujo su actividad a permanecer oculto a los ojos de sus compañeros de infortunios, que para tratar con él, habían de permanecer esperando la audiencia pedida por escrito y por intermedio de los edecanes... Los civilistas no quieren ya nada con el ratero del 4 de febrero. Están, tiempo ha, escarmentados de hacerle remesas de oro, que en vez de ser dedicadas al levantamiento, solo iban a llenar los bolsillos, el bolsón de la Paca-Paca y el paño verde de las mesas de juego...

Balta que ha quedado muy desacreditado en Costa Rica; república en la que, por haber sido sobornado en su carácter de Director del Ramo de Petróleo, por una poderosa Compañía yanqui (con 3,000 colones: ¡quién lo creyera!) 
fue obligado por el Gobierno a renunciar. Es notorio en San José el encamotamiento del chino con una tonadillera; encamotamiento que hubo de poner a la Sra. Hughes -la suegra de Guillermo Porras- en la necesidad de embarcar a dos de sus hijas, con la filial misión de "enfriar al taita..." Por los periódicos de Lima he sabido que Balta está en estos días en dares y tomares con Leguía. ¡Vaya con la bendita oposición!...

Luján ha quedado en Costa Rica. Sé que le pagan sus dietas.

Encinas -que también recibe sus "emolumentos"- se ha dirigido a Honduras. Pensaba continuar a México, de donde había recibido la palabra de aliento del desventurado gobernador de Yucatán, pero la revolución ha echado por tierra sus expectativas. En marzo se encaminará a Londres, pues quiere matricularse como alumno de la Universidad de Oxford. Al salir de San José estaba en malas relaciones con Luján. ¡Ah, cholo! A nosotros no nos dirigió ni una postal....

Gran gusto me ha producido lo que me refieres sobre el gran Doig. ¡Cuánto me alegro que no haya perdido el año! En los momentos de hastío y de desilusión -que no son pocos en los escuetos cuartos de los desterrados- es uno de mis consuelos el pensar que almas como la de Carlos Doig y Lora sufren por nosotros. ¿No es uno de los mejores motivos de orgullo? ¿No constituye ello una firme esperanza? Mucho temo que no le hayan entregado mi carta, escrita el día de año nuevo. Mucho más temo aún que crea que lo he olvidado. Hace cuatro días -el 23- en que nos llegó un mensaje de Carreño y Ugarte, recibí un saludo de Doig, y me lo imaginé con sus perfiles 1830, a lo Mariano José de Larra. Dile que con el portador de la "buena nueva" le envié mi felicitación calurosa por los triunfos de diciembre, y las expresiones fervientes de mi fraternidad invariable.

Recibí el recorte del artículo de Raúl. Ya he dado a este -en postal certificada- mi enhorabuena por su última producción, que es una maravilla de delicadeza literaria y de acierto crítico. Creo que el artículo de Raúl es el mejor prólogo 
que Valle puede poner a la colección de sus poesías. Debe decirse que Porras está ya cuajado. Ello me ha alegrado inmensamente, tanto más cuanto que su triunfo significa la mejor canción con tanta mentalidad fría, simuladora y "sanchezca"...

Celebro, asimismo, bastante que el "esclarecido" Abelardo haya pasado en sus exámenes. Al Viejo le ha producido gran satisfacción la noticia, y mucha risa el curioso incidente con Araujo Álvarez. Oportunamente -creo que a mediados del presente- el director del Diario de Panamá nos remitió el "Boletín N 6 del Perú"; Boletín en el que inmediatamente descubrimos la huella maléfica y "jacobina” de Soliz. Comunica a este que no le he escrito por temor de que mi trabajo -a causa de la censura- fuera perdido. Salúdalo con mucho afecto en mi nombre, lo mismo que del Viejo y de Óscar.

Mucho gusto he tenido al leer la carta de León, tan rotunda (hijo de su padre), tan cordial, tan explosiva. El Viejo está muy agradecido. Si hay tiempo se la contesto hoy. Manifiéstale mis sentimientos cordiales, y reitérale mi fe en su valor.

Aún no he recibido respuesta de Zulen, al cual los autores panameños han enviado ya algunas obras a las que pronto se agregarán otras. Exprésale mis recuerdos y reclámale el Boletín 6, que tengo deseos de leer. Hazle presente que se olvidó de poner como apéndice de mi artículo la singular hoja suelta de los rotos desertores, huidos a Chanchamayo.

Recién he recibido una carta de Valle, de fecha 4 de diciembre. Aunque aquel me anuncia la remisión -ordenada por Vasconcelos- de gran número de obras (Constitución de Querétaro, legislación obrera y la colección de clásicos), parece que la Marconi se ha robado todos los paquetes. Así lo deduzco de las cartas de mis hermanos, en las que, a pesar de la minuciosidad que acostumbran para todo lo mío, no me comunican nada.

Antes de recibir el recorte que me has enviado, conteniendo el artículo de Raúl sobre Valle, yo había enviado a éste 
el que extraje de un $\mathrm{N}^{\circ}$ de Variedades que me regaló el peruano Belisario Castro. Asimismo, le he mandado un comentario de Roberto Mac León Estenás, aparecido en $L a$ Prensa. Quiera Dios que ambas cosas lleguen a poder del destinatario. Temo que los revolucionarios den mala cuenta de la correspondencia del tácito obregonista hondureño. Como Valle prepara un libro sobre los piratas, le he dirigido, certificada, la interesante obra del istmeño Juan B. Sosa sobre la Vieja Panamá, destruida por Morgan. Le he acompañado algunas postales con vistas de las ruinas de la histórica sede del descubrimiento de nuestra tierra.

En mi carta del 1 de enero te agradecí ya las oportunísimas y nobles gestiones que hicieras con toda eficacia para trasladar a casa de mis tías Rosas mis libros y objetos de minería. Una de mis mayores preocupaciones era que las mensualidades continuaran corriendo y que los implacables recibos cercenaran el presupuesto de mi familia, que, si cuando vivíamos juntos era modesto, hoy con la separación nuestra y fraccionamiento de nuestra renta, resulta misérrimo. Creo de más manifestarte nuevamente mi agradecimiento. Recordando la profundísima generosidad de tu espíritu, comprendo la honda satisfacción que experimentarías al darme nueva muestra de fraternidad. No voy a hacer una frase, sino a decir un axioma: en las grandes almas, la abnegación es una modalidad de egoísmo...!

Siento que Mitincito no haya recibido la postal que le remití... ¡Cómo he gozado pensando en mis "apostólicas" cuitas a favor de Doig! Te encargo para el Presidente Nato del Bilis Club mis mejores recuerdos.

Mucho sentiría que Raúl creyera que no le he escrito. Para disuadirlo, y sin dejar de echarle, como es realidad, la culpa a la Marconi y al censor oficial Enrique Marquina, hazle presente que es inconcebible que a amigos de la 2 da. serie les haya enviado postales, y no a él uno de los epónimos.

Solo he recibido, hasta la fecha, respuesta de Ugarte, el que, 
según lo que me dice, estará ya en el Cuzco. Me ha hecho sonreír el comienzo de su postal: "Mucho recuerdo ahora los recortes que me enviaba Ud. de la "Secretaría" y de $L a$ Prensa.

He tomado debida nota de tu advertencia sobre el portador de tu carta, al cual probaré algún día mi agradecimiento.

¿Qué es de Carlos Alberto González? No te olvides de darle en mi nombre un gran apretón de manos.

No me ha causado sorpresa el infame cable del corresponsal en Lima de la Associated Press. El autor ha sido seguramente Ceil N. Griffis, que, al proceder así ha sido digno sirviente de su patrón. Cisneritos se ha comprado al Viejo con su hidalga actitud.

Mi vida aquí no puede ser más monótona. Los días tienen una uniformidad que aplasta. El enervante calor no despierta deseos de trabajar. Se carece del estímulo de la amistad en esta tierra de zambos gritones, confianzudos, palanganas e ignorantes. Sigo estudiando inglés con... Oliver, lo mismo que las cosas de Panamá, principalmente las que alguna relación tiene con nuestra patria. Puede ser que me anime a escribir algo al respecto pero no aseguro. Con franqueza: ¡en este infierno uno se siente un animal!...

Fijándome en ello, van ya diez páginas y me parece que recién he comenzado.

Estimo en todo lo que valen tus sentidas palabras sobre nuestra amistad. Estamos completamente de acuerdo. En cuanto a la bondad mía de que hablas, solo acepto tal mérito como correspondencia a lo que en todos momentos supiste manifestarme. Abandonado, negado, y, probablemente, hasta vituperado por aquellos en que tanto confié y a quienes consideraba mis íntimos, fuiste tú quien únicamente no dudó un instante de la honradez con que en todo tiempo procedí, de la espontaneidad de mis sentimientos, y de la desinteresada finalidad de todos mis propósitos. Cuando, entre soplones y al lado del Mayor Adrián Mendoza, se me conducía a la isla de San Lorenzo, al volver en la noche la 
mirada a la costa que se alejaba y que denunciaba el parpadeo de las luces, y reconstruir en la memoria el cuadro espiritual que dejaba, quién sabe hasta cuándo. Yo te colocaba, emocionado, al lado de mi madre y de mis hermanos. Fue por ello que al llegar a Paita, no vacilé al dirigirme a ti, en reemplazar el vocativo que tan injustamente habíamos empleado durante tanto tiempo, traicionando la realidad palpitante de nuestra amistad efectivamente fraternal. Ante la defección casi total de mi sangre y de mis relaciones personales, creo que nada he perdido al pensar que hay un amigo como tú que ha creído en mí y ha sabido ser consecuente como nadie a los que yo podría denominar mis estallidos afectos. Esto, cual en mi carta de diciembre, tampoco es retórica, querido Colombroño!

¡Cuanto más querría escribirte! Más la mano cede, la memoria falla, y el Viejo me apremia para que lo acompañe a dar una vuelta por el apacible y pintoresco barrio de la Labana.

Aquel te recuerda con el mismo afecto de siempre, y me encarga trasmitirte su más cordial saludo. Digo lo propio respecto de Óscar.

Que las vacaciones sean fecundas para ti en distracciones y triunfos y que saluden la victoriosa aparición de "Vivanco".

Un gran abrazo de tu affm. camarada,

Jorge Guillermo

En: ACMBT 


\section{Primera y última hoja de la carta de Jorge Guillermo a Jorge Basadre}

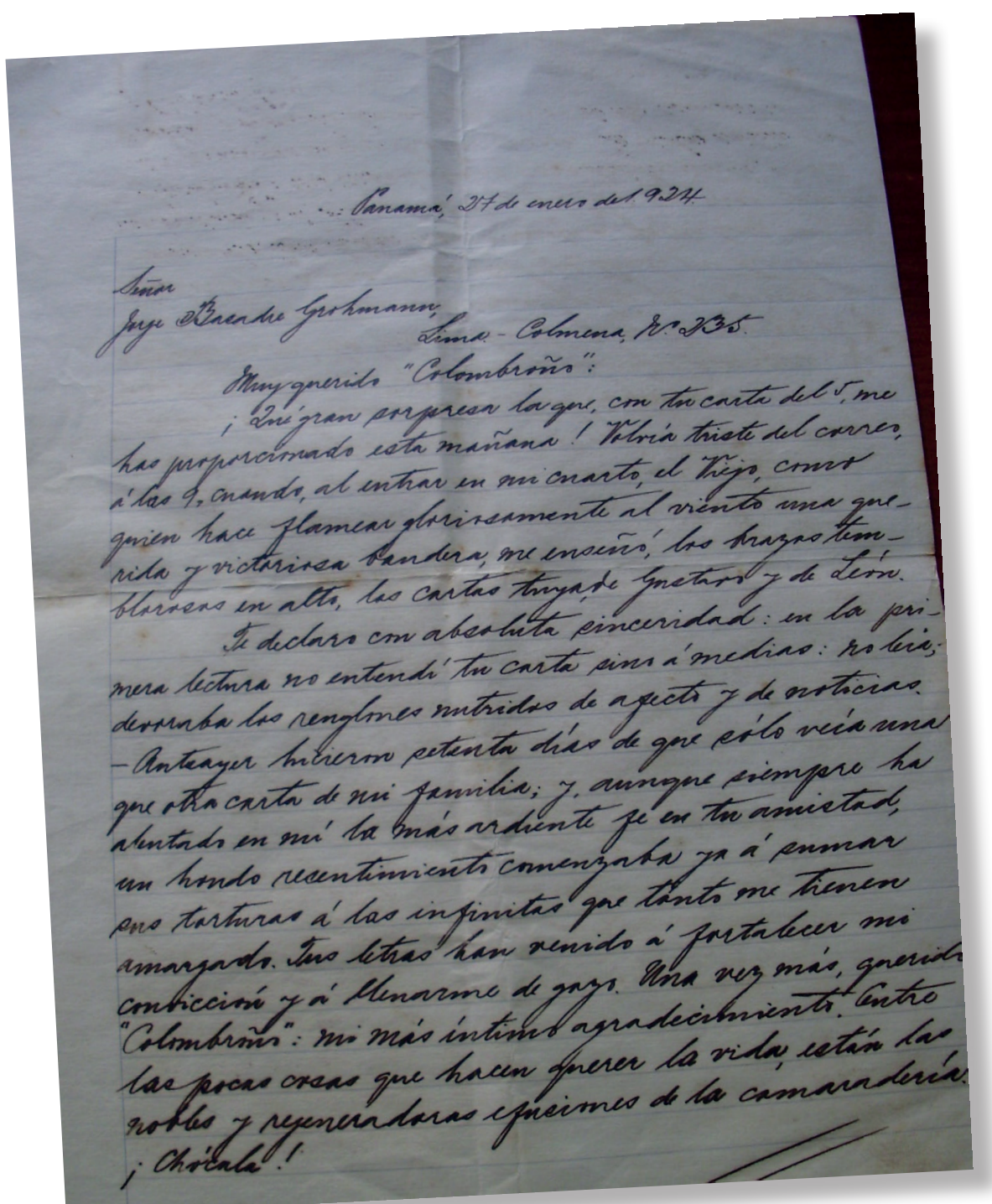


Los historiadores de la generación del centenario: sus cartas juveniles

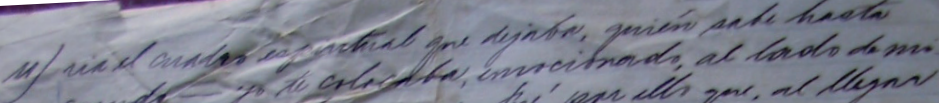

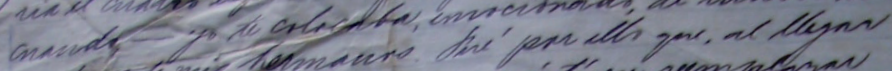

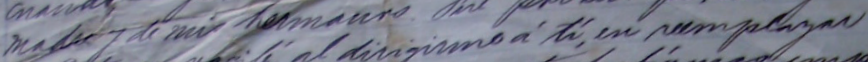

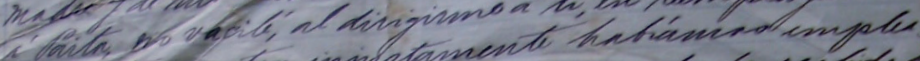

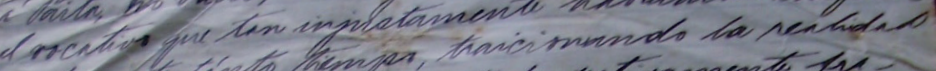

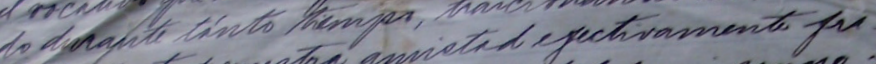

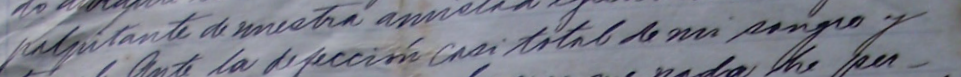

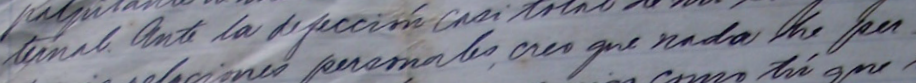

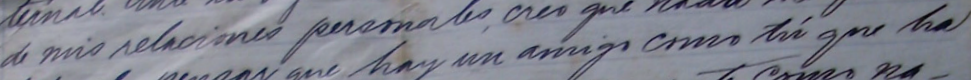

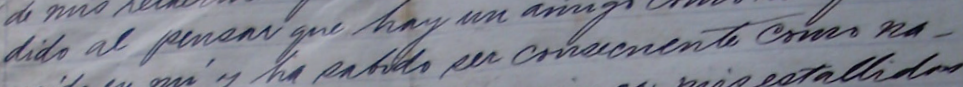

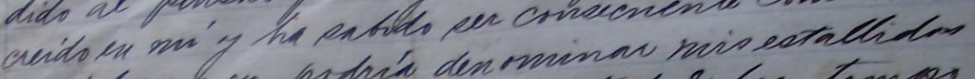

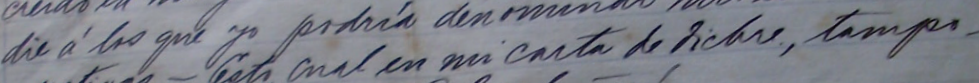

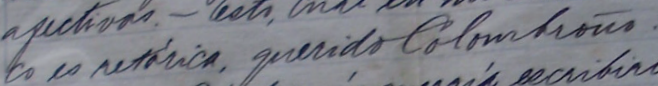

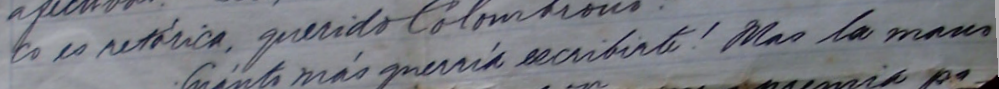

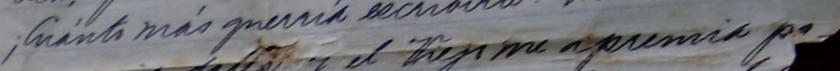

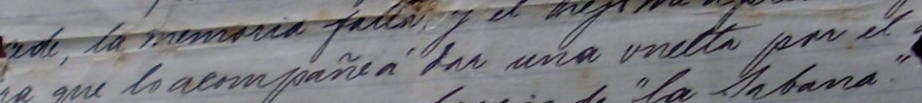

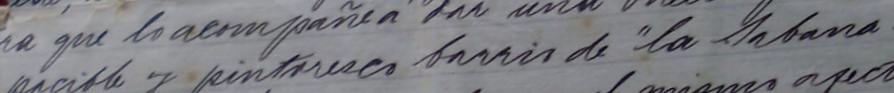

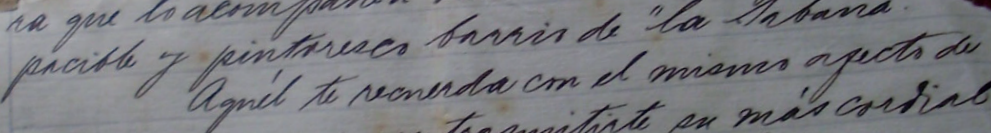

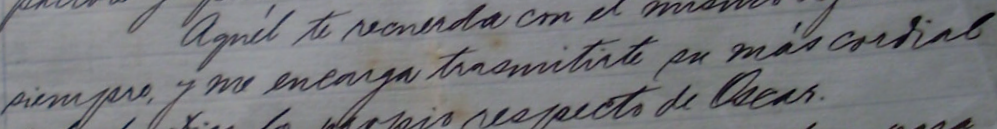

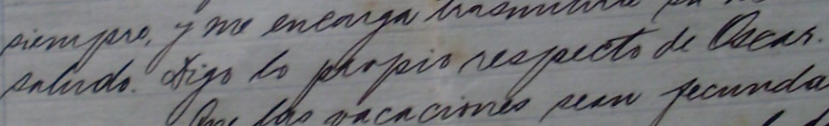

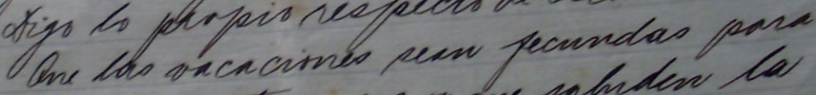

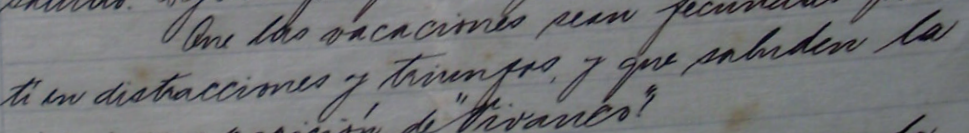
victavisen aparienión de "Diviones!

312

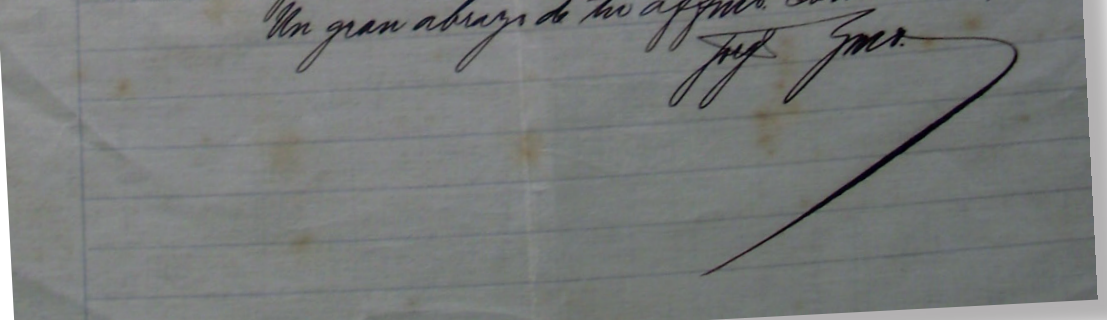

Revista del Instituto Riva-Agüero 


\title{
Anexo 3
}

\section{Carta de Jorge Basadre a Emilia Romero (BNM)}

\author{
Barcelona, 24 de Julio de 1934
}

Señorita

Emilia Romero

Av. Grau 281

Miraflores

Muy distinguida Señorita:

Tengo que agradecerle a usted de todo corazón que me haya enviado el folleto con la conferencia de Jorge Guillermo sobre Palma. No tengo derecho a proclamarme el mejor amigo de Jorge. Todos los que le conocieron si no fueron amigos suyos, debieron serlo. En la vida además de trabajar por y sobre el Perú, no hizo otra cosa que ir sembrando afectos. No soy, pues, sino uno más entre sus amigos; pero pienso con orgullo cuando recuerdo el pasado y con angustia cuando pienso en el porvenir (tan acostumbrado he estado siempre a su compañía) que soy uno de sus más viejos amigos.

No sé qué epidemia canalla hay en el Perú en los últimos tres años, que aún gente bien enceguece; solo de esta manera puedo explicarme que en el volumen con las conferencias sobre Palma fuese omitida la bella y sólida contribución de Jorge. Ahí no para la cosa, porque he leído el discurso de José de la Riva Agüero inaugurando la Biblioteca de la Universidad Católica, una alusión a Jorge presentándole como jacobino o sectario, y yo que admiro el talento, la erudición y las dotes morales de Riva Agüero, me pasmo al descubrirle tan incomprensivo y tan injusto con quien fue su leal amigo, con quien precisamente le llama "maestro" en la conferencia que usted me envía. En una carta que escribí hace muchos días a Raúl Ferrero, catedrático de la Universidad Católica, apelaba a su testimonio para ratificar mi convicción de que ha sido desfigurada la nobilísima significación intelectual de 
Jorge siempre muy por encima de toda mezquina bandería, demasiado amplia y desinteresada para caber dentro del casillero de los demagogos y de los agitadores.

De otras cosas no tengo derecho a hablar; pero de lo que se relaciona con Jorge sí. Le conocí en 1919 yo recién acababa de entrar en la universidad. El común gusto a los libros nos hizo pronto camaradas. Mi afición histórica se decidió al lado de la suya ya formada. Hay amistades muy sólidas que se quiebran o acallan cuando de la vanidad o de la emulación se trata. El proverbio dice que el enemigo es el del oficio. Jorge era la excepción para confirmar esta regla. Su cordialidad conmigo en aquellos ańos como en los últimos tiempos, en vez de disminuir aumentaba por el hecho de que trabajábamos el mismo campo. Le debo una presentación que era un elogio a todas luces exagerado y prematuro en uno de sus "Domingos Históricos" en La Prensa de 1921; el conocimiento de muchos datos por él suministrados incluyendo apuntes de su padre; la publicación de mis libros en Lima, por él gestionada y obtenida ante los hermanos Rosay; y su ayuda y su estímulo y su acicate permanentemente en grandes y pequeńas ocasiones.

No era el amigo con el que no se hace sino conversar y cambiar impresiones; ni era el amigo que de la amistad hace un medio, un trampolín. Era el amigo que sabía apoyar y acompañar; y el amigo sin utilitarismo ni sordidez. Desgracia que me pasara, ya sabía yo que si él podía me ayudaría. Las veces que estuve preso a él le debí la libertad, que luego, en la calle otros se jactaban ante mí de haberla conseguido. No solo en el caso mío o de los míos, sino en el de personas extrañas. Constaté varias veces que en las horas de duelo o de quebranto, extremaba su espíritu servicial. Varias veces le dije que resultaba un negocio tenerlo al lado. Cuando ahora pienso que he de regresar a Lima y no ha de estar allí, sé que he de sentirme inmensamente más solo.

Todos estos desahogos que le escribo son sin duda demasiado egoístas, están hechos desde un punto de vista exclusivo. Sé, sin embargo, que lo que fue él conmigo fue con los de- 
más. Una de sus más grandes virtudes era la de emplear el calor de su corazón. Era el más formidable contraste con un mundo frío y mendaz.

Lo que aportó a la cultura peruana no sé si allá lo comprenden bien. En primer lugar, precisa aclarar que ha muerto en el momento preciso en que acababa de llegar a la verdadera madurez. A pesar de su inmenso talento y de su inmensa cultura, Jorge había sido antes, en el fondo un niño en el buen sentido de la palabra. Todas sus maravillosas reservas morales y espirituales fluían tal vez de este hecho envidiable. Ahora bien, sin dejar de ser moral y espiritualmente lo que fue siempre, su talento estaba alcanzando ya, como dice usted, la plenitud de su desarrollo.

Pero descartando esta verdad, quedan otras realidades inconmovibles. Jorge significa primordialmente una radical, una auténtica, una irrevocable vocación de cultura, lejos de todo cálculo, por la cultura en sí. Será un exceso, una imprudencia, un heroísmo si se quiere; pero esto no se puede negar. Heroísmo, hay que repetir la palabra, cuando en el Perú no hay para la cultura compensaciones económicas y a veces se regatean las obras. Jorge lo sabía y no le importó.

¿Y al servicio de qué puso esa vocación de cultura? No la puso al servicio de un partido ni de un dogma ni de un interés de clase o de familia. La puso al servicio del Perú. Cuanto escribió, cuanto estudió de veras, cuanto divulgó tuvo como tema el Perú y si no el Perú, América. Viajó y no le fascinaron los temas exóticos sino muy superficialmente. Sufrió y sufrió su familia, pero no renegó de su patria, aunque fuera consciente de sus defectos. Fue un gran peruano que sirvió mucho y honró mucho y amó mucho al Perú.

En su obra escrita (obra de juventud) cabe hallar muchas facetas. Hay la faceta de elogio o exaltación. Los modelos que tomó (Rodríguez de Mendoza, Gálvez, etc.) los tomó no para hacer propaganda ideológica, sino para presentar algunas vidas puras y verticales para entonar y vigorizar el culto de los valores nacionales. Su enorme capacidad de admiración buscaba (al empezar Jorge sus búsquedas his- 
tóricas) temas que con ella consonara. Lo que en realidad le entusiasmaba eran las figuras ejemplares, los aristócratas de la inteligencia y de la cultura. Así fue como pudo exhumar los nombres de Rodríguez de Mendoza, sacerdote, José Gálvez, tribuno radical y Bartolomé Herrera, maestro del conservadurismo peruano. (No hay que olvidar que sobre "San Carlos en los días de Herrera" versa uno de los más bellos estudios de Jorge y que empezó a editar, por propia iniciativa, las obras de su maestro).

Más tarde, su biografía de Vidaurre (de la cual solo publicó algunos capítulos) se coloca en otro plano. Ya es el biógrafo socarrón, malicioso, más maduro, que va a penetrar hasta en el último repliegue de su personaje. Hay algo de común, sin embargo, entre los anteriores estudios biográficos y el referente a Vidaurre: es el afán por ir haciendo la historia civil del Perú. No es cierto lo que dicen los textos dando importancia única a los grandes mariscales y generales. El aporte de los civiles que casi nadie había estudiado antes empieza Jorge a reivindicarlo.

La Historia de América señala otra faceta de su obra. Escribe y publica el segundo tomo en momentos grávidos. No se ha hecho otro resumen tan completo, tan documentado y tan claro como su resumen sobre las guerras de la Independencia americana.

Allí está también su estudio sobre Palma. Leyéndolo he encontrado puntos de vista, conceptos y expresiones que me han sorprendido. Había cambiado mucho en los dos años y pico que dejé de verle.

316 Todavía había que recordar lo mucho que hizo para reeditar y revelar documentos. Empezó esta labor en los "Domingos Históricos" de La Prensa en 1921, la continuó superándola en el Boletín del Museo Bolivariano de 1929 a 1930, la publicación de las obras de Herrera forma parte del mismo plan. Todo el que quiera estudiar en adelante la Independencia o la República deberá usar las fuentes documentales que Jorge puso expeditas para el servicio público. 
Lo que publicó es poco, poquísimo en comparación con lo que deja inédito, apenas empezado o planeado. La vida materialmente no le dejó hacer más. Esa es la espantosa injusticia que hay en la muerte de los jóvenes, muy diferente de la muerte de los ancianos: éstos siempre, por más queridos que sean, dejan tras de sí una faena ya cumplida, una misión terminada o por terminarse en tanto que con la muerte de los jóvenes se trunca lo más inmenso que hay: las posibilidades.

En fin, en medio de todo queda el consuelo de haber sabido que en los últimos tiempos de su vida, Jorge halló la felicidad al lado de usted. Reiterándole mi muy sincero agradecimiento por haberse acordado de mí y rogándole me disculpe la impertinencia y extensión de esta carta, reciba usted mi saludo muy cordial.

Jorge Basadre

BNM, Fondo Valle, ERHER Expe. 24. 


\section{Primera y última hoja de la carta de Jorge Basadre a} Emilia Romero

mi mur sinero agradecimiento nor haberse acribato de mi Togánisle me lisculge la impertinencia extensión de esta carta, reciba ustes misalues muz conial.
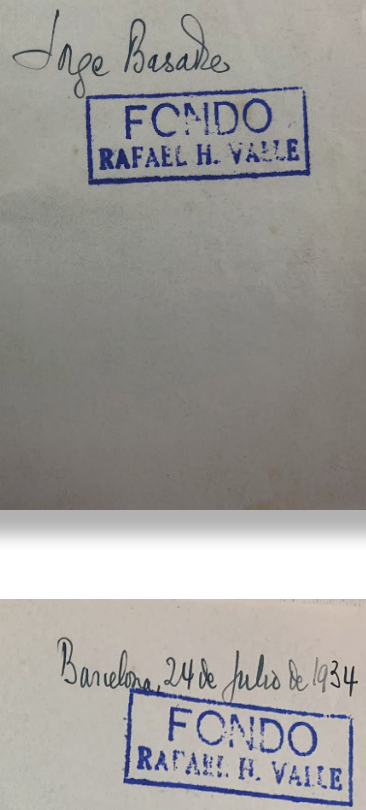

Av.Grau 281. Mivafloes.

Muqvisinguibe señovita: Tengo que agrablecerles austes ke toob Corazoi que me hara enviato el follets con la conferencia de /oge Suillemo wohe Palma. No lengo verecho a proclamaime el mejor amigo de/oge. Toros los que e conscieron sinífueron anigos aur os, delieron serb. In la vida abemás te trabajar por sobre el Perré, no hizo otia cosa que ir sembranto afectos. Noso i pues, sins uno más entie ras amigos; pero pienso 
Recibido: 15 de noviembre del 2020

Aprobado: 25 de mayo del 2021

\section{Documentos citados}

Archivo Casa Museo Basadre Tacna (ACMBT)

Carta de Jorge Guillermo Leguía a Jorge Basadre. 16 de diciembre de 1921. ACMBT.

Carta de Jorge Guillermo Leguía a Jorge Basadre. 27 de enero de 1924. ACMBT.

Archivo Histórico de Riva Agüero (AHIRA)

Carta de Jorge Guillermo Leguía a Víctor Andrés Belaúnde. 23 de octubre de 1927. AHIRA.

Biblioteca Nacional de México (BNM)

Carta de Raúl Porras a Jorge Guillermo Leguía. México, 15 de setiembre de 1921. BMN, Fondo Valle.

Carta de Jorge Guillermo Leguía: Un estudiante peruano en el destierro se dirige al Presidente Leguía. 10 de diciembre de 1923. BNM, Fondo Valle.

Carta de Raúl Porras a Jorge Guillermo Leguía. 12 octubre de 1924. BNM, Fondo Valle.

Carta de Rafael Heliodoro Valle a Raúl Porras. 29 de abril de 1925. BNM, Fondo Valle, ERHC EXP 195, 19211953, 58 doc.

Carta de Jorge Basadre a Raúl Porras. 18 de octubre de 1931 desde Nueva York. BNM, Fondo Valle ERHC EXP. 223, 1931-1949, 24 doc. 


\section{Referencias bibliográficas}

Basadre, J.

La Biblioteca Nacional de Lima 1943-1945. Lima: Eds. de la Biblioteca Nacional, III. https:// www.bcn.cl/obtienearchivo? id=document os/10221.1/58925/2/181991.pdf\&origen=BDigital.

Basadre, J.

(1968) Historia de la República del Perú. Lima: Ed. Universitaria.

Basadre, J.

(1975) La vida y la historia, ensayos sobre personas, lugares y problemas. Lima: Fondo del Libro del Banco Industrial del Perú.

Basadre, J.

(1989) Prólogo (1937). En Estudios históricos de Jorge Guillermo Leguía (pp. 13-17). Lima: Asociación Cultural Integración.

Capuñay, M. A.

(1951) Leguía. Vida y obra del constructor del gran Perú. Lima: Cía. de Impresiones y Publicidad.

Casalino, C.

(2017) Centenario. Celebraciones de la Independencia 19211924. Lima: Municipalidad Metropolitana de Lima. https://publicacioneslima.pe/wp-content/ uploads/2018/10/munilibro-10.pdf

320

Castilla, M.

(2011) La generación arielista y la construcción del "otro" en el Perú del novecientos. Los Trabajos y Los Días, 3(2). http://sedici.unlp.edu.ar/handle/10915/31564

Chapas Bezanilla, M. Á.

(2004) Rafael Heliodoro Valle, humanista de América. México, D.F.: Universidad Nacional Autónoma de México e Instituto de Investigaciones Bibliográficas. 
Cueto Caballero, $M$.

(1982) La reforma universitaria de 1919. Universidad y estudiantes a comienzos de siglo (Tesis para optar el grado de bachiller en historia). Pontificia Universidad Católica del Perú, Facultad de Letras y Ciencias Humanas, Lima.

Dagicour, O.

(2010) Le “mythe” Leguia : images et pouvoir sous le Oncenio, Perou 1919-1930. https://core.ac.uk/download/ pdf/52807688.pdf

Delgado, W. (2008)

El alma fáustica del maestro Raúl Porras (1897-1960). http://borradordecatedrarpp.blogspot.com/2008/09/ el-alma-fustica-del-maestro-ral-porras.html

Denegri Luna, F.

(1994) Aporte de la generación del 900 a la identidad peruana. Boletín del Instituto Riva Agüero, 21, 219220. http://repositorio.pucp.edu.pe/index/bitstream/handle/123456789/113888/9687-Texto\%20 del\%20art\%C3\%ADculo-38326-1-10-20140729. pdf? sequence $=2 \&$ is Allowed $=\mathrm{y}$

Gálvez, C.

(1990) Los estudios históricos de Jorge Guillermo Leguía. Histórica, XIV (l). http://revistas.pucp.edu.pe/index.php/historica/article/view/8814

Guerra Martinièri, M.

(1984) Historia general del Perú. La república contemporánea, t. XII. Lima: Milla Batres.

Guerra Martinièri, M.

Historia general del Perú. La república 1900-1948, t. VIII. Lima: Milla Batres. 
Guzmán Sánchez, J. G.

(1997) Vida y obra de Jorge Guillermo Leguía (Tesis para optar el grado de licenciatura en historia). Pontificia Universidad Católica del Perú, Facultad de Letras y Ciencias Humanas, Lima.

Riva Agüero, J. de la

(1962) Comentario a la conferencia de Jorge Guillermo Leguía sobre Palma. En Estudios de literatura peruana: Del Inca Garcilazo a Eguren (pp. 423-425). Lima: Pontificia Universidad Católica del Perú, Instituto Riva-Agüero. (Obras completas, II).

Romero, E.

(1940) Bibliografía de Jorge Guillermo Leguía. Separata del Boletín Bibliográfico de San Marcos, XIII(3).

Romero de Valle, E.

(1966) Diccionario manual de literatura peruana y materias afines. Lima: Universidad Mayor de San Marcos.

Sánchez, L. A.

(1969) Testimonio personal. Memorias de un peruano del siglo XX (t. I-II.). Lima: Ediciones Villasán.

Sánchez, L. A.

Victor Raúl Haya de la Torre. Luis Alberto Sánchez. Correspondencia (t. I-II.). Lima: Mosca Azul Editores. T. I-II.

322 Sánchez, L. A.

(1989) Postfacio a modo de prefacio (1936). Historia y biografía de Jorge Guillermo Leguía (pp. 13-20). Lima: Asociación Cultural Integración.

Valle, R. H.

(1934) Jorge Guillermo. La Crónica, 15 de marzo de 1934. 